\section{Empoderamento na Recuperação do Serviço: Implicações na Percepção de Equidade e Lealdade do Cliente}

\author{
Wandick Leão e Juliana Bonomi Santos
}

\section{RESUMO}

Estudos em Recuperação do Serviço (RS) mostram que a equidade no processo de RS é crucial para a satisfação e lealdade do cliente. Esse processo é realizado por funcionários de atendimento que, com suas ações, influenciam a sensação de equidade. Assim, estratégias ligadas ao processo e à gestão desses funcionários, como o empoderamento, podem expandir o nível de equidade que, por sua vez, pode estimular a lealdade dos clientes. Esse trabalho investiga tais relações através de um levantamento de dados, por meio de questionário com clientes em serviços bancários. Para analisar os dados, foram empregadas análises fatoriais exploratória e confirmatória e modelagem por equações estruturais. Os resultados mostram que o empoderamento traz maior equidade ao processo de RS e promove a lealdade dos clientes. Além de comprovar essas relações, esse trabalho contribui com a literatura, ao promover a integração de conceitos de diferentes campos de conhecimento que beneficiam a gestão de serviços. No caso deste estudo, o empoderamento (Operações), que depende da seleção adequada e treinamento do pessoal de atendimento (Recursos Humanos), a equidade e a lealdade em serviços (Marketing). Sob a perspectiva gerencial, sugere-se que as empresas de serviços implementem treinamentos específicos em RS para seus funcionários de atendimento, promovendo também o seu empoderamento.

Palavras-chaves: Empoderamento. Equidade. Lealdade. Recuperação do Serviço. Falhas em Serviços Bancários. Bancos.

\section{Empowerment in Service Recovery: Implications in the Client's Perception Regarding Fairness and Loyalty}

\section{ABSTRACT}

Studies in Service Recovery (SR) demonstrate that equity in SR process is crucial to the customer's satisfaction and loyalty. Front office employees are responsible for this process which, with their actions, they influence the perception in fairness. Thus, strategies focused on improving processes and the employees' work performance, such as the empowerment, may expand qualities such as equity and, in turn, lead to customer loyalty. This work investigates these relationships through a survey on banking services. Data were analyzed through exploratory and confirmatory factor analyses and structural equation modelling. The results show that the empowerment brings greater equity to the SR process; consequently, it influences positively customer loyalty. In addition to proving these scenarios, this work contributes to the related literature, by integrating concepts from different fields of knowledge that benefit SR and studies in service management. Especially regarding empowerment (Operations), that involves human resources training and qualification (Human Resources Management), equity and loyalty in services (Marketing). From a managerial perspective, it is suggested that service organizations should implement specific SR training for their front-line employees, which promotes their empowerment.

Keywords: Empowerment. Fairness. Loyalty. Service Recovery. Failures in Banking Services. Banks.
Recebido em: 12/09/2017 Aprovado em: 16/02/2018 Última Modificação: 14/04/2018

D) Check for updates

Wandick Leão (iD,

Professor Auxiliar do Insper - Instituto de Ensino e Pesquisa Doutorando em Administração de Empresas pela FGV-EAESP Mestre em Administração de Empresas pelo PPGA-FEI

wandicklf@insper.edu.br

Juliana Bonomi Santos (D), Professora da FGV-EAESP $\mathrm{PhD}$ em Management Science, Lancaster University Management School

juliana.bonomi@fgv.br 


\section{Introdução}

A prestação de serviços está além de sorrisos, palavras bonitas e um aperto de mãos (Michelli, 2013; Schneider, 1990). Afinal, embora as empresas se esforcem em oferecer serviços com alto nível de qualidade, nota-se que neste setor falhas acontecem e são difíceis ou impossíveis de se eliminar (DeWitt \& Brady, 2003). Todavia, a insatisfação decorrente dessas falhas não deve se tornar algo comum entre os clientes (Hart, Heskett, \& Sasser, 1990). Para isto, a empresa deve recuperar o serviço. A Recuperação do Serviço (RS) é um processo realizado após o surgimento de falhas, que tem por finalidade resolver problemas, satisfazer e reter o cliente e melhorar o processo de serviço (Grönroos, 1988; Johnston, Clark, \& Shulver, 2012; Miller, Craighead, \& Karwan, 2000; Tax \& Brown, 2000).

Vários trabalhos em RS afirmam que as ações que acontecem neste processo são percebidas pelos clientes quanto à sua equidade, isto é, se elas são equilibradas e justas diante da falha ou problema que aconteceu (Crisafulli \& Singh, 2016; Giovanis, Athanasopoulou, \& Tsoukatos, 2015; Matos \& Leis, 2013; Migacz, Zou, \& Petrick, 2018; Ozuem, Patel, Howell, \& Lancaster, 2017; Park \& Ha, 2016;). A percepção de equidade afirma que as partes envolvidas em uma troca devem estar satisfeitas e sentir equilíbrio nessa relação (Andreassen, 2000). Crisafulli e Singh (2016) e Tax e Brown (1998) afirmam que a percepção de equidade se divide em três dimensões: a interacional, que trata de como o funcionário realizou o atendimento (educado, esforçado, preocupado); a processual, que verifica os processos que a empresa dispõe para tratamento da reclamação (flexível, rápido, fácil); e a distributiva, que se preocupa com a solução para a reclamação (se ela atendeu a princípios como igualdade, necessidade e proporção). Essas dimensões agrupadas, além de proporcionarem satisfação (Giovanis et al., 2015), podem gerar a permanência do cliente com a mesma empresa que realizou a RS, isto é, podem gerar lealdade (Migacz et al., 2018).

No entanto, a equidade precisa ser exercida para que benefícios como esses realmente aconteçam. Os funcionários de atendimento têm papel fundamental na geração da sensação de equidade e, por isso, suas ações são de vital importância em situações de RS (Robinson, Neeley, \& Williamson, 2011; Zhang, Dai, \& He, 2015). Curioso é que apesar da literatura reconhecer a importância do empoderamento dos funcionários de atendimento na RS (Boshoff \& Allen, 2000; Bowen \& Johnston, 1999; Bowen \& Lawler, 1995; Hart et al., 1990; Miller et al., 2000), ela não explora o impacto que o mesmo poderia gerar nas dimensões de equidade.

Percebe-se, por exemplo, em relação à equidade interacional, que o empoderamento poderia melhorar a interação dos funcionários junto aos clientes, como na forma em que eles explicarão a falha na honestidade das informações, na cortesia do tratamento, no esforço e na empatia deles no momento da RS (Choi, Kim, Lee, \& Lee, 2014; Daily \& Huang, 2001; Lashley, 1998; Li \& Fang, 2016; Slack, Brandon-Jones, \& Johnston, 2018; Van Looy, Desmet, Krols, \& Van Dierdonck, 1998). Por outro lado, a equidade processual pode ser afetada pelo empoderamento, em relação às questões como o controle do processo e das decisões, acessibilidade, tempo/velocidade e a flexibilidade dos funcionários de atendimento no momento da RS (Boshoff \& 
Allen, 2000; Bowen \& Lawler, 1992; Chebat \& Kollias, 2000; Hill, 2000; Smith \& Karwan, 2010; Sok \& O'Cass, 2015). Por último, atribuir empoderamento aos funcionários de atendimento parece influenciar também na equidade distributiva, isto é, na solução que eles entregam aos clientes, a qual devem representar princípios de necessidade, igualdade e proporção (Brown, Cowles, \& Tuten, 1996; Grönroos, 2009; Ogbeide, Böser, Harrinton, \& Ottenbacher, 2017; Sasser \& Fulmer, 1990; Schlesinger \& Heskett, 1991; Tax \& Brown, 1998).

Desta forma, o objetivo deste artigo foi examinar o relacionamento e seus efeitos entre os construtos de empoderamento, equidade e lealdade na RS. Esse exame foi realizado através de um survey com clientes de bancos, que passaram por falhas/problemas e posterior RS. Este é um contexto relevante para se estudar a RS, pois em serviços bancários os clientes têm relações de longo prazo (Boshoff \& Leong, 1998) e os bancos sempre estão preocupados em criar novas estratégias de RS (Duffy, Miller, \& Bexley, 2006). Para a análise dos dados foram empregadas Análises Fatoriais Exploratória/ Confirmatória e Modelagem por Equações Estruturais. Os resultados mostram que o empoderamento influencia positivamente a lealdade dos clientes. Isso ocorre pois o empoderamento aumenta a percepção de equidade que os clientes têm em relação ao processo de recuperação. Assim, observa-se que equidade é um construto mediador para se alcançar a lealdade dos clientes. Todavia, esta mediação é parcial, havendo outros fatores que podem explicar a relação entre empoderamento e lealdade.

Do ponto de vista teórico, este trabalho contribui com a Gestão de Serviços, ao propor um modelo mais robusto sobre o alcance da lealdade na RS, que integra conceitos do Marketing, de Operações e Recursos Humanos $(\mathrm{RH})$. Ao fazer isso, o modelo mostra que a equidade tem capacidade para mediar a relação empoderamento e lealdade, aspecto pouco explorado na literatura até o presente momento. Como contribuições práticas, este trabalho propõe que empresas de serviços que buscam melhores resultados, focados na operação interna ou no relacionamento com os clientes, devem propor treinamentos específicos em RS e empoderar os seus funcionários.

Este artigo está organizado da seguinte forma: Na segunda seção são ilustrados rapidamente os temas atuais e os mais pesquisados em RS. Em seguida, na mesma seção, são explorados os construtos deste estudo. Depois, são elaboradas as hipóteses da pesquisa. Na terceira seção são explicados os procedimentos metodológicos. Na quarta tem-se a análise dos dados e, finalmente, na quinta seção são produzidas a discussão e as considerações finais deste estudo.

\section{Quadro Teórico, construtos e hipóteses da pesquisa}

\section{Panorama sobre pesquisas em Recuperação do Serviço (RS)}

Apesar da profusão de trabalhos na década de 1990, a RS continua crescendo como campo de pesquisa (Li \& Fang, 2016). Trabalhos empíricos disponíveis aos gestores de serviços indicam a sua viabilidade como uma 
ferramenta estratégica (Boshoff \& Allen, 2000; Choi \& Choi, 2014). Alguns deles demonstram vários benefícios após o processo de RS, como a satisfação dos clientes (Kau \& Loh, 2006; Mattila \& Patterson, 2004), o aumento da lucratividade (De Ruyter \& Wetzels, 2000; Johnston \& Michel, 2008), a recomendação "boca a boca" (Choi \& Choi, 2014; Jones \& Farquhar, 2007), a lealdade dos clientes (Chou, 2015; Wang, Hsu, \& Chih, 2014) e o aprimoramento dos processos e do sistema de serviços (Michel, Bowen, \& Johnston, 2009; Smith, Karwan, \& Markland, 2012).

No entanto, quando a RS não dá certo, isto é, a empresa falha em sua segunda chance, ela cai no que a literatura denomina como double deviation, (Edvardsson, Tronvoll, \& Höykinpuro, 2011; Johnston \& Fern, 1999). Existe também o "paradoxo" da RS, evento no qual os níveis de satisfação do cliente são maiores após a falha e sua recuperação do que se a empresa houvesse prestado o serviço perfeitamente - sem erros - já na primeira vez (Gohary, Hamzelu, \& Pourazizi, 2016; Matos, Henrique, \& Rossi, 2007).

Estudos mais recentes têm se preocupado em analisar questões que interferem nos resultados da RS, como o ambiente de trabalho e a satisfação dos funcionários em poder aplicar a RS (Choi et al., 2014; Edvardsson et al., 2011), os tipos de compensação (Bambauer-Sachse \& Rabeson, 2015; Li \& Fang, 2016), as garantias na RS (Crisafulli \& Singh, 2016; McCollough \& Gremler, 2004), a cocriação do cliente (Dong, Evans, \& Zou, 2008; Guo, Lotz, Tang, \& Gruen, 2016) e, por fim, efeitos moderadores como idade, gênero e cultura do cliente (Moliner-Velázquez, Ruiz-Molina, \& Fayos-Gardó, 2015; Xu, Marshall, Edvardsson, \& Tronvoll, 2014).

Apesar dessas diversas relações e resultados abordados pela literatura, um dos temas que mais se destaca ainda é a identificação das ações necessárias para que a RS seja eficaz, alcançando a satisfação e/ou lealdade dos clientes (Boshoff, 2005; Johnston \& Michel, 2008; Leão, Santos, \& Hernandez, 2017; Wang \& Mattila, 2011). Nessa vertente de análise, alguns estudos também abordam como ações de RS são percebidas em termos de equidade por esses clientes (Crisafulli \& Singh, 2016; Matos \& Leis, 2013; Migacz et al., 2018; Wirtz \& Mattila, 2004). Além disso, existe uma discussão de que a RS só pode ser efetiva se usar conceitos de três campos de conhecimento - Marketing, Operações e RH - dado que no processo de RS existem três elementos: cliente, processo e funcionários (Leão, 2016; Michel et al., 2009; Moliner-Velázquez et al., 2015).

Este trabalho se encaixa nesta vertente teórica, pois busca integrar conceitos dessas diferentes áreas de conhecimento. Para isso, analisa a influência do empoderamento (Operações), que depende do treinamento e adequada seleção de pessoas para recebê-lo $(R H)$ na percepção de equidade e, por consequência, na lealdade dos clientes (Marketing). Os conceitos de empoderamento, de equidade e lealdade na RS, bem como a relação entre eles, serão discutidos em seguida.

\section{Empoderamento na Recuperação do Serviço (RS)}

Na maioria dos serviços, o tempo é crítico para a empresa e para o cliente. $\mathrm{Na}$ verdade, o cliente geralmente escolhe uma empresa por conveniência e economiza tempo em comparação com outra alternativa, por exemplo, uma 
refeição fast food (Chase \& Haynes, 2000). Portanto, quando os clientes têm algum problema em uma experiência de serviço, eles não querem ser atendidos por outras pessoas ou serem convidados a voltar no momento em que o gerente esteja presente, apenas querem ter o seu problema resolvido (Boshoff \& Allen, 2000). Para isso, as empresas precisam ter funcionários de atendimento com poder para resolver esses problemas (Ogbeide et al., 2017; Pranic \& Rhoel, 2012). O ideal seria que eles tivessem autoridade para tomar decisões imediatas. Caso contrário, oportunidades de vendas, de recuperar o serviço e corrigir erros/problemas de qualidade, não serão usadas de forma adequada (Grönroos, 2009). Para auxiliar esse tipo de conflito, uma estratégia conveniente seria o empoderamento (Bowen \& Johnston, 1999; Choi et al., 2014).

Empoderamento, de acordo com Bowen e Lawler (1992), significa fornecer aos funcionários de atendimento: (1) informações sobre o desempenho da empresa; (2) recompensas baseadas no desempenho da empresa; (3) conhecimentos que permitam que eles compreendam e possam contribuir para o desempenho da empresa e (4) poder para tomarem decisões que influenciam a direção e o desempenho da empresa. Isto é, o empoderamento trata da concessão de poder ao funcionário, para que ele possa agir em favor dos clientes e influenciar o desempenho da empresa (Bowen \& Lawler, 1992, 1995).

Para Hart et al. (1990), empoderamento diz respeito ao acesso a determinados recursos que permitam aos funcionários tomar decisões, condição essa que, em muitas empresas, apenas os gestores possuem. Cumpre destacar que o empoderamento não elimina a hierarquia, direção ou a responsabilidade de cada um e nem concede liberdade total aos funcionários. Essa seria uma visão bem limitada da essência e dos benefícios dessa estratégia (Berry, 1996).

O empoderamento no campo da RS tem grande relevância (Ashill, Rod, \& Carruthers, 2008; Boshoff, 2005; Bowen \& Johnston, 1999; Leão et al., 2017; Li \& Fang, 2016; Ogbeide et al., 2017; Tax \& Brown, 1998, Zhang et al., 2015). Uma de suas principais singularidades é o fato de poder fornecer a RS de acordo com o ponto de vista do cliente (Brown, Cowles, \& Tuten, 1996). Esta possibilidade acontece em virtude do contato frequente que existe entre os funcionários de atendimento e os clientes. Este nível de envolvimento permite que eles conheçam bem as necessidades do cliente, principalmente quando algo dá errado, pois eles estão mais próximos e em melhor posição para definir o que os clientes necessitam (Boshoff, 1997; Boshoff \& Allen, 2000). Através dessa abordagem é possível a correção imediata de falhas em serviços, o que consequentemente, na maioria das vezes, acaba por exceder as expectativas do cliente (Bowen \& Lawler, 1995).

Em muitos casos em que há a necessidade de RS, os funcionários de atendimento precisam de poder para aplicar ações criativas e flexíveis, que às vezes podem infringir em parte as normas e a regulamentação da empresa. Tais atitudes são vistas com indiferença e relutância pela gerência (Boshoff \& Allen, 2000). Em várias empresas, existem processos que necessitam da aprovação do superior direto, que muitas vezes está ocupado, atrasando, assim, a reação e frustrando tanto o cliente como o funcionário (Bateson \& Hoffman, 2001). 
O problema é que questões formais como essas amarram os funcionários (Boshoff \& Leong, 1998; Grönroos, 2009), não permitindo uma reação rápida e eficaz em caso de falhas em serviços. Essas características, que são bem vistas pela maioria dos clientes, podem converter possíveis sentimentos que eles venham a ter de frustação ou irritação em satisfação (Bateson \& Hoffman, 2001; Bowen \& Lawler, 1992). Isto é, ao invés de facilitar as operações de atendimento, a gestão constrói barreiras que prejudicam a excelência do serviço, como políticas e procedimentos que exigem que até as decisões mais básicas sejam realizadas apenas pela gestão (Boshoff \& Allen, 2000).

Assim, quando há empoderamento, os funcionários conseguem agir de forma mais eficiente e promover um processo de RS mais adequado. A literatura aponta alguns benefícios promovidos pelo empoderamento que geram impacto no desempenho da empresa e na percepção do cliente, como: respostas mais rápidas e flexíveis (Bowen \& Lawler, 1995; Hill, 2000; Smith \& Karwan, 2010), soluções mais assertivas (Grönroos, 2009; Schlesinger \& Heskett, 1991; Sok \& O'Cass, 2015), satisfação dos funcionários (Ashill et al., 2008; Van Looy, Krols, Buyens \& Vandenbossche, 2003) e o aumento da competitividade e lucratividade (Bowen \& Lawler, 1992, 1995).

Tax e Brown (1998), afirmam que a equidade da solução aumenta quando os funcionários têm flexibilidade para fornecer a compensação, com base na circunstância e nas necessidades dos clientes. Funcionários com poder de decisão são mais motivados e empenhados em envolver-se na melhoria de questões relacionadas ao seu ambiente de trabalho (Daily \& Huang, 2001; Sok \& O'Cass, 2015). Além disso, o empoderamento também envolve a responsabilidade para lidar com as reclamações. Desta forma, os funcionários se preocupam com a clareza na comunicação com os clientes, uma das questões mais sensíveis na RS (Lashley, 1998). Van Looy et al. (1998), alegam que o empoderamento proporciona maior qualidade na interação funcionário e cliente. Isso acontece porque eles acabam interagindo com mais entusiasmo e autoestima (Choi et al., 2014; Slack et al., 2018). Para Chebat e Kollias (2000), Hill (2000) e Sok e O'Cass (2015), o empoderamento proporciona flexibilidade na prestação de serviços - quebrando velhas normas e scripts da empresa. Essa é uma qualidade importante que aplicada com eficiência, pode trazer soluções personalizadas já no local de atendimento. Por fim, RíoLanza, Vázquez-Casielles e Díaz-Martín (2013) afirmam que as empresas devem capacitar os funcionários para que eles possam, em situações de RS, aplicar melhores ações que impactem a percepção de equidade do cliente, em relação à comunicação, ao processo e à solução. Este trabalho sugere que o empoderamento pode auxiliar neste sentido, afinal, ele pode trazer maior eficiência ao processo de RS (Leão et al., 2017).

\section{Equidade na Recuperação do Serviço (RS)}

As pesquisas iniciais em RS falam de um conteúdo ou pacote de ações. No trabalho de Bell e Zemke (1987), os autores sugerem a primeira "receita" da recuperação, constituída por cinco ingredientes. Após o acréscimo dos estudos realizados por Bitner, Booms e Tetreault (1990), Johnston (1995) e Kelley, Hoffman e Davis (1993), essa receita se resume em (Johnston \& Michel, 2008): 
- Reconhecimento da falha pela empresa/funcionário

- Empatia junto ao cliente

- Pedido de desculpas

- Acolhimento e Solução do problema

- Garantias e Compensação

Durante certo tempo, os estudos em RS mantiveram-se atrelados a essas ações ou etapas do processo e a relação desse processo com outputs, como a satisfação e a lealdade dos clientes. Todavia, esses estudos revelaram-se estáticos com o tempo, requerendo novas e mais profundas pesquisas, que examinassem o impacto dessas ações na percepção dos clientes. Preenchendo esse espaço, Tax, Brown e Chandrashekaran (1998), sugeriram que ações de RS deveriam ser percebidas pelo cliente de forma equitativa ou justa. Na maioria dos estudos em RS, nacionais (Santos \& Fernandes, 2007; Silva \& Lopes, 2014) e internacionais (Migacz et al., 2018; Xu et al., 2014) usa-se o termo justiça. Todavia, seguindo as recomendações de Grönroos (2009), esse termo parece ter uma conotação de ordem jurídica. Logo, a palavra "equidade" parece ser mais adequada ao contexto da gestão de serviços, sendo, portanto, o termo adotado nesta pesquisa. A percepção de equidade sugere que as partes envolvidas em uma troca devem ambas estar satisfeitas e sentir igualdade nessa relação (Andreassen, 2000; Ozuem et al., 2017). Ou seja, essas relações devem ser equilibradas (Smith, Bolton, \& Wagner, 1999), uma vez que o cliente aguarda uma solução justa para o seu problema (Giovanis et al., 2015; Mattila \& Patterson, 2004).

Por outro lado, a falta de equidade ou ações de RS desbalanceadas causam atritos entre a empresa de serviços e seus clientes (Boshoff \& Leong, 1998), dado que não há o alcance ou a restauração dos sentimentos de equidade entre as partes (De Ruyter \& Wetzels, 2000). Assim, é necessário compreender quais são os comportamentos adequados no processo de RS para restaurar o senso de equidade dos clientes (Mattila \& Patterson, 2004). A percepção de equidade compreende como o cliente avalia as diversas ações despendidas pela empresa, quanto ao processo de recuperação ou prestação do serviço (Seiders \& Berry, 1998). Essa avaliação é realizada através das seguintes dimensões (Crisafulli \& Singh, 2016; Matos \& Leis, 2013; Xu et al., 2014): interacional (interação), processual (processos) e distributiva (resultado/solução). A seguir, a explicação de cada dimensão do modelo de equidade no processo de RS.

\section{Equidade Interacional}

Esta dimensão se relaciona com aspectos do tratamento disponibilizado ao cliente alvo da falha. Ela tem relação com os funcionários de atendimento (interações/comportamento), que devem prover um esforço de recuperação ou atendimento o mais autêntico, honesto e cortês possível (McCollough, Berry, \& Yadav, 2000; Seiders \& Berry, 1998). Os critérios essenciais para compor essa dimensão são: explicação da falha, honestidade, cortesia, esforço e empatia (Tax et al., 1998). Para Wirtz e Mattila (2004), independente da rapidez da RS, os clientes devem ser tratados com respeito e cortesia. 
Johnston e Mehra (2002), afirmam que a realização de um contato telefônico junto ao cliente reclamante é fundamental, não para confirmar o registro da reclamação, mas como oportunidade de apresentar um lado mais humano aos clientes, assegurando de que a falha é tratada de forma delicada e criteriosa e não como algo rotineiro e impessoal. Os clientes que recebem explicações da empresa que aceita a responsabilidade por um erro ou problema estarão mais dispostos a fazer negócios com ela novamente (Conlon \& Murray, 1996). Essa dimensão causa impacto relevante quando a empresa reconhece o erro e inicia a RS com um pedido de desculpas (Smith et al., 1999).

\section{Equidade Processual}

Esta dimensão diz respeito às ações processuais da RS. Nela, o cliente leva em consideração questões como flexibilidade, responsividade e conveniência da empresa em resolver a falha (Blodgett, Hill, \& Tax, 1997; Mattila, 2001; Smith et al., 1999). Os critérios essenciais que compõem esse construto são relacionados ao controle do processo e das decisões, acessibilidade, tempo/velocidade e flexibilidade (Río-Lanza et al., 2013).

Em relação à qualidade dos serviços, o cliente leva em consideração não só o resultado entregue, mas também o processo responsável por realizar essa entrega (Zeithaml, Parasuraman, \& Berry, 2014). Tax e Brown (1998) destacam que diante de um problema, o acesso conveniente e a rápida resolução aumentam a equidade processual. Por outro lado, essa dimensão examina o impacto processual da tomada de decisões, proporcionando qualidade nas relações cliente e prestador de serviços (Hocutt, Bowers, \& Donavan, 2006). Em resumo, essa dimensão está preocupada com o processo responsável por resolver o problema do cliente (McColl-Kennedy \& Sparks, 2003).

\section{Equidade Distributiva}

O último critério que o cliente analisa é a solução da RS, isto é, o que foi entregue a ele. Essa solução deve suprir qualquer vazio ou desequilíbrio que o cliente venha a perceber quanto às dimensões anteriores. A solução deve compensar não só a falha, mas o tempo, esforço e energia despendidos pelo cliente. Em síntese, esse critério refere-se à avaliação que o cliente faz do resultado recebido em uma experiência inicial de serviço ou solução recebida em uma situação de RS. Ou seja, ele avalia se o que ele recebeu foi justo, proporcional e atendeu suas expectativas ou necessidades (McCollough et al., 2000; Tax \& Brown, 1998). Além da resolução da falha/problema, fazem parte dessa dimensão compensações fornecidas para apaziguar uma situação negativa, como restituições, créditos e descontos (Mattila \& Patterson, 2004; Río-Lanza et al., 2013).

\section{Lealdade na Recuperação do Serviço (RS)}

Gremler e Brown (1996) definem lealdade em serviços como o comportamento no qual o cliente realiza suas compras em um mesmo provedor, tem atitudes positivas em relação a ele e sempre que necessário 
o considera como única fonte de consumo. Esse construto segue a operacionalização feita por Boshoff (2005), que o aferiu sob o prisma do cliente ter vontade de recomendar seu banco para outras pessoas e se ele tinha a intenção de continuar usando o mesmo banco no futuro.

Em primeira instância, a RS tem sido utilizada como um caminho para se atingir a satisfação de clientes que sofreram com falhas. No entanto, quando isso acontece, geralmente a lealdade deles também é afetada (Chou, 2015; De Ruyter \& Wetzels, 2000; Giovanis et al., 2015; Kau \& Loh, 2006; Migacz et al., 2018; Miller et al., 2000). De acordo com Tax e Brown (1998), para resolver problemas em serviços de modo mais eficiente, empresas de classe mundial têm investido maciçamente na gestão de relacionamentos com foco na lealdade dos clientes (Brown, 2000).

Colgate e Norris (2001) apontaram em seu estudo que, alguns clientes com muito tempo de conta em um banco, e que sofreram com falhas que não foram devidamente recuperadas, sentem-se "traídos" pelo banco e acabam deixando esse relacionamento. Como se pode notar, as falhas em serviços têm relevante potencial para destruir a lealdade. No entanto, a eficiente aplicação de técnicas de RS, serve para manter ou até mesmo aumentar os níveis de lealdade dos clientes (Miller et al., 2000). Para Swanson e Kelley (2001), procedimentos treinados e bem estabelecidos de RS conseguem aumentar a lealdade dos clientes, bem como propagar a recomendação boca a boca.

Através de um survey, Hoffman, Kelley e Rotalsky (1995), descobriram que não importa o tipo da falha ou a sua importância, pois em geral é possível recuperar clientes de vários incidentes. Os achados de suas pesquisas mostraram que $75 \%$ dos clientes foram retidos. Mattila (2001), através de um experimento com três cenários em distintos serviços (restaurante, cabeleireiro e lavanderia), descobriu que a oferta de desculpas e um desconto de $20 \%$ como ações de RS conseguiram relevante impacto, tanto na satisfação como na lealdade dos clientes, tendo maior efeito no caso dos serviços de corte de cabelo do que nos serviços de restaurante e lavagem a seco. Smith et al. (1999) também sugerem que em situações de falha, a RS tem capacidade substancial, tanto para satisfazer o cliente como para reforçar a sua lealdade. Em geral, respostas de RS que não coincidem com o que os clientes esperam, prejudicam significativamente a satisfação e a lealdade dos mesmos (Miller et al., 2000).

\section{Hipóteses da Pesquisa}

\section{A relação entre empoderamento e lealdade na RS}

O empoderamento dos funcionários de atendimento promove a lealdade dos clientes que passam por processos de RS. Essa estratégia pode gerar respostas mais rápidas e flexíveis (Bowen \& Lawler, 1995; Hill, 2000; Smith \& Karwan, 2010) e soluções mais assertivas (Grönroos, 2009; Schlesinger \& Heskett, 1991; Sok \& O'Cass, 2015) na RS. Serviços bem executados e processos de RS eficazes são características que geram lealdade por parte dos clientes (Eccles \& Durand, 1998). O empoderamento, além de criar uma abordagem de trabalho criativa, flexível e personalizada, parece também ter capacidade para melhorar o relacionamento com os clientes, estimulando 
a lealdade dos mesmos (Bowen \& Lawler, 1992; Chebat \& Kollias, 2000). Nessa linha, Boshoff e Allen (2000) argumentam que o empoderamento é uma estratégia crucial - principalmente em situações de RS - para promover uma melhor relação entre o cliente e o funcionário de atendimento e melhorar o processo de serviço.

Discutindo o equilíbrio necessário entre os requisitos de mercado e os recursos de operações, Craighead, Karwan e Miller (2004) sugerem que respostas de RS que não atendem às necessidades dos clientes podem causar impacto negativo tanto na satisfação quanto na lealdade deles. Por outro lado, se o problema é bem resolvido, os clientes vão fazer mais recomendações boca a boca do que se o serviço tivesse sido bem executado na primeira oportunidade (Eccles \& Durand, 1998). Dessa forma, como o empoderamento melhora o potencial de resolver os problemas dos clientes (Grönroos, 2009; Schlesinger \& Heskett, 1991; Sok \& O'Cass, 2015), essa estratégia também tem potencial para aumentar a lealdade deles (Leão et al., 2017; Ogbeide et al., 2017). Por fim, sabe-se que técnicas de RS - tais como o empoderamento -, quando bem executadas podem proporcionar e manter a lealdade dos clientes (Miller et al., 2000; Tax \& Brown, 1998). Em vista do exposto, sugere-se a primeira hipótese deste trabalho:

H1: O empoderamento dos funcionários de atendimento influencia positivamente a lealdade dos clientes após a RS.

No entanto, as equidades interacional, processual e distributiva podem ter um papel relevante para explicar o motivo pelo qual o empoderamento promove maior lealdade nos clientes, como explorado a seguir.

\section{A relação entre equidade e lealdade na $R S$}

A percepção de equidade é uma avaliação psicológica feita pelos clientes em relação à experiência de serviço. Isto é, são eles que avaliam se as ações foram equilibradas em relação à interação, ao processo e ao resultado do serviço, independentemente se os funcionários empoderados elevam o desempenho delas ou não. Nesta linha, a literatura em RS mostra, por meio de estudos empíricos, que ações para melhorar a percepção de equidade - interacional, processual e distributiva - auxiliam o desempenho da RS e promovem a lealdade dos clientes (Conlon \& Murray, 1996; Giovanis et al., 2015; Mattila, 2001; Santos \& Fernandes, 2007; Silva \& Lopes, 2014; Smith et al., 1999; Tax \& Brown, 1998). Além disso, em um estudo recente que avaliou o impacto de vários construtos na lealdade do cliente, Giovanis et al. (2015) mostraram que, apesar da qualidade na prestação do serviço e no relacionamento com os clientes serem importantes para a lealdade, a equidade foi o construto com maior impacto.

De forma semelhante, Ogbeide et al. (2017) afirmam que a forma como os funcionários de atendimento lidam com situações de reclamação pode influenciar tanto a satisfação como a lealdade dos clientes. Isso ocorre porque, como diferentes estudos mostraram, ações de RS realizadas pelos funcionários de atendimento impactam a percepção de equidade dos clientes em relação às dimensões interacional (Choi et al., 2014; Daily \& Huang, 2001; 
Li \& Fang, 2016; Slack et al., 2018), processual (Bowen \& Lawler, 1992, 1995; Smith \& Karwan, 2010; Sok \& O'Cass, 2015) e distributiva (Grönroos, 2009; Ogbeide et al., 2017; Tax \& Brown, 1998). Diante destas premissas, sugere-se que a equidade influencia a lealdade dos clientes. Essa premissa se desdobra nas seguintes hipóteses:

H2a: A equidade interacional influencia positivamente a lealdade do cliente após a RS.

H2b: A equidade processual influencia positivamente a lealdade do cliente após a RS.

H2c: A equidade distributiva influencia positivamente a lealdade do cliente após a RS.

\section{A Relação entre Empoderamento e Equidade na RS}

A literatura demonstra que o empoderamento na RS tem capacidade substancial para influenciar positivamente a percepção de equidade dos clientes. Primeiramente, na dimensão interacional, pois ele permite aos funcionários de atendimento: 1) maior liberdade sobre como explicar a falha; 2) maior honestidade ao explicar o(s) motivo(s) da falha; 3) tranquilidade e responsabilidade, melhorando a cortesia no tratamento e o esforço para promover a RS (Bowen \& Lawler, 1992; Choi et al., 2014; Daily \& Huang, 2001; Lashley, 1998; Li \& Fang, 2016; Slack et al., 2018; Van Looy et al., 1998). Por outro lado, o empoderamento pode influenciar a equidade processual, pois ele reduz: 1) a "rigidez" do processo; 2) o número de atividades executadas e o tempo de espera para a tomada de decisões; 3) aumenta a velocidade do processo e a 4) flexibilidade dos funcionários de atendimento (Boshoff \& Allen, 2000; Bowen \& Lawler, 1992, 1995; Brown et al., 1996; Chebat \& Kollias, 2000; Hill, 2000; Smith \& Karwan, 2010; Sok \& O'Cass, 2015; Tax \& Brown, 1998). Por último, atribuir empoderamento aos funcionários de atendimento parece influenciar também a dimensão distributiva da equidade, uma vez que quando tais funcionários se sentem empoderados, eles entregam melhores resultados/soluções aos clientes. Soluções estas que, diante de um problema/falha, devem representar para o cliente o alcance de princípios como 1) necessidade, 2) igualdade e 3) proporção (Brown et al., 1996; Grönroos, 2009; Ogbeide et al., 2017; Sasser \& Fulmer, 1990; Schlesinger \& Heskett, 1991; Tax \& Brown, 1998).

Dessa forma, dado que as ações relacionadas às dimensões de equidade são realizadas pelos funcionários de atendimento, que podem ou não serem dotados de empoderamento, apresenta-se a terceira e última hipótese deste trabalho:

H3a: O empoderamento dos funcionários de atendimento influencia positivamente a equidade interacional.

H3b: O empoderamento dos funcionários de atendimento influencia positivamente a equidade processual.

H3c: O empoderamento dos funcionários de atendimento influencia positivamente a equidade distributiva. 


\section{Procedimentos metodológicos}

\section{População, Variáveis e Coleta dos dados}

A população adotada para a coleta de dados foi de indivíduos que tiveram problemas resolvidos em serviços bancários. Essa escolha se faz relevante, dado que esses serviços são caracterizados por relações pessoais e de longo prazo (Boshoff \& Leong, 1998). Em seu estudo sobre bancos, Johnston (1995) descobriu que dentre as principais fontes de insatisfação dos clientes, estavam: a falta de honestidade, de equidade, de confiança, de capacidade de resposta, de disponibilidade e de funcionalidade. Duffy et al. (2006) afirmam que em resposta aos problemas, os bancos usam várias estratégias de RS como a coleta de reclamações dos clientes, pedidos de desculpas, correção do problema e a compensação. Para Jones e Farquhar (2007), os bancos devem criar pontos de contato satisfatórios para os clientes, sejam eles presenciais ou remotos (telefone ou internet). Outra característica importante é o fato das experiências de serviço em bancos envolverem diversas formas de contato, como encontros "cara a cara", comunicações telefônicas, caixas automáticos, e-mails e similares (Michel, 2004; Ramachandran \& Chidambaram, 2012).

Para a coleta dos dados primários foi desenvolvido um questionário pré-testado com 183 respondentes. A análise fatorial exploratória sugeria unidimensionalidade entre os construtos de equidade interacional e processual. Houve também problemas de interpretação do questionário visualizado em smartphones, especialmente em relação ao número de opções disponíveis na escala Likert. Após o aperfeiçoamento das instruções sobre o questionário, bem como das escalas de equidade, a coleta de dados final foi empregada com estudantes e pessoas comuns que têm contato com um dos pesquisadores.

Todas as variáveis utilizadas no survey são originárias da revisão da literatura proposta neste trabalho. As variáveis empregadas no estudo possuem escala Likert de 7 pontos, com ancoragem em 1=Discordo totalmente e 7=Concordo totalmente para todas as variáveis. Excetua-se desse padrão a variável sobre a importância do problema, que teve ancoragem em 1=Sem importância e $7=$ Muito importante. Na primeira seção, o questionário inicia com uma pergunta dissertativa: Descreva o problema que aconteceu com você. Desta forma, o respondente era impelido a se lembrar do problema e descrevê-lo em detalhes, para posteriormente responder com maior validade. Este procedimento se ampara na Técnica do Incidente Crítico (TIC), que pede ao respondente que ele/ela se lembre de uma experiência de serviço: boa ou ruim e a descreva em detalhes (Lorenzoni \& Lewis, 2004; Miller et al., 2000; Stauss \& Weinlich, 1997). Uma das vantagens desta técnica é que ela é útil na identificação de ações específicas que promovam eficiência e garantia na RS (McCollough et al., 2000). Além disso, ela tem relevante validade externa (Hocutt et al., 2006; Wirtz \& Mattila, 2004), aumenta o conhecimento de um fenômeno sobre o qual pouco se sabe (Bitner et al., 1990), relaciona-se com acontecimentos reais (Goldstein, Johnston, Duffy, \& Rao, 2002; Lewis \& Clacher, 2001) e o respondente tem a oportunidade de descrever a experiência em seus próprios termos e linguagem familiar (Edvardsson \& Ross, 2001; Edvardsson, 1992). 
Após esta questão dissertativa, seguiam-se as questões sobre importância, quando e onde aconteceu o problema. Na segunda seção, a pergunta dissertativa abordava como o banco e/ou funcionários haviam tratado o respondente no momento da reclamação. Em seguida, eram expostas as questões sobre empoderamento, bem como as questões sobre a equidade interacional. A terceira seção versava sobre as equidades processual e distributiva. A última seção discorria sobre a lealdade do respondente junto ao banco. Na tabela 1 são ilustrados os construtos, suas variáveis, autores e adaptações realizadas para a coleta dos dados.

Tabela 1. Construtos, variáveis, autores e alterações

\begin{tabular}{|c|c|c|c|}
\hline Construto & Variável(is) & Autor(es) & Alteração(ões) \\
\hline $\begin{array}{l}\text { Importância do } \\
\text { problema }\end{array}$ & Qual importância você daria ao problema que aconteceu com você & Mattila (2001) & $\begin{array}{l}\text { Tradução e adaptação para } \\
\text { o português }\end{array}$ \\
\hline \multirow{4}{*}{ Empoderamento } & $\begin{array}{l}0 \text { funcionário para quem eu reclamei teve que encontrar alguém para } \\
\text { resolver o meu problema }\end{array}$ & \multirow{2}{*}{ Boshoff (2005) } & \multirow{2}{*}{$\begin{array}{l}\text { Tradução e adaptação } \\
\text { inversa para o português e } \\
\text { mudança da escala Likert } \\
\text { de } 5 \text { para } 7 \text { pontos }\end{array}$} \\
\hline & A minha reclamação foi passada de um funcionário para outro & & \\
\hline & $\begin{array}{l}0 \text { funcionário teve que aguardar a autorização do seu supervisor para } \\
\text { continuar resolvendo o meu problema }\end{array}$ & \multirow{2}{*}{$\begin{array}{l}\text { Boshoff \& } \\
\text { Leong (1998) }\end{array}$} & \multirow{2}{*}{$\begin{array}{l}\text { Adaptação dos cenários } \\
\text { para itens em ordem } \\
\text { inversa, tradução e } \\
\text { adaptação para o português }\end{array}$} \\
\hline & $\begin{array}{l}0 \text { funcionário não conseguiu resolver todo o meu problema sozinho, } \\
\text { tendo de encaminhá-lo ao Gerente }\end{array}$ & & \\
\hline \multirow{5}{*}{$\begin{array}{l}\text { Equidade } \\
\text { Interacional }\end{array}$} & $\begin{array}{l}\text { Os funcionários do banco pareciam estar dizendo a verdade sobre } 0 \\
\text { meu problema }\end{array}$ & \multirow{5}{*}{$\begin{array}{l}\text { Tax et al. } \\
(1998)\end{array}$} & \multirow{5}{*}{$\begin{array}{l}\text { Tradução e adaptação para } \\
\text { o português/contexto de } \\
\text { bancos }\end{array}$} \\
\hline & $\begin{array}{l}\text { Os funcionários do banco me deram uma boa explicação sobre } \\
\text { porque esse problema aconteceu }\end{array}$ & & \\
\hline & $\begin{array}{l}\text { Os funcionários do banco pareciam muito preocupados com o meu } \\
\text { problema }\end{array}$ & & \\
\hline & Senti que fui bem tratado(a) pelos funcionários do banco & & \\
\hline & $\begin{array}{l}\text { Os funcionários do banco promoveram todos os esforços possíveis } \\
\text { para lidar com o meu problema }\end{array}$ & & \\
\hline \multirow{5}{*}{$\begin{array}{l}\text { Equidade } \\
\text { Processual }\end{array}$} & $\begin{array}{l}0 \text { banco me deu oportunidade para eu me manifestar sobre a solução } \\
\text { que ele encontrou para o meu problema }\end{array}$ & \multirow{5}{*}{$\begin{array}{l}\text { Tax et al. } \\
(1998)\end{array}$} & \multirow{5}{*}{$\begin{array}{l}\text { Tradução e adaptação para } \\
\text { o português/contexto de } \\
\text { bancos }\end{array}$} \\
\hline & Foi fácil descobrir para quem reclamar neste banco & & \\
\hline & 0 banco respondeu rapidamente à minha reclamação & & \\
\hline & $\begin{array}{l}\text { Na hora de reclamar o banco me deu a chance de eu contar a minha } \\
\text { versão da história }\end{array}$ & & \\
\hline & $\begin{array}{l}0 \text { banco teve boa vontade para adaptar seus procedimentos a fim de } \\
\text { atender às minhas necessidades }\end{array}$ & & \\
\hline \multirow{4}{*}{$\begin{array}{l}\text { Equidade } \\
\text { Distributiva }\end{array}$} & Ao resolver o meu problema o banco me deu o que eu precisava & \multirow{4}{*}{$\begin{array}{l}\text { Mattila (2001) } \\
\text { Mattila (2001) } \\
\text { Blodget et al. } \\
\text { (1997) } \\
\text { Mattila (2001) }\end{array}$} & \multirow{4}{*}{$\begin{array}{l}\text { Tradução e adaptação para } \\
\text { o português/contexto de } \\
\text { bancos }\end{array}$} \\
\hline & A solução que eu recebi para esse problema foi justa & & \\
\hline & $\begin{array}{l}\text { Considerando o problema que eu tive sinto que o banco me deu uma } \\
\text { compensação adequada }\end{array}$ & & \\
\hline & Em termos de solução recebi o que eu esperava & & \\
\hline \multirow{4}{*}{ Lealdade } & Falo coisas positivas deste banco para outras pessoas & \multirow{4}{*}{ Mattila (2001) } & \multirow{4}{*}{$\begin{array}{l}\text { Tradução e adaptação para } \\
\text { o português/contexto de } \\
\text { bancos }\end{array}$} \\
\hline & $\begin{array}{l}\text { Incentivo amigos, familiares e conhecidos a realizarem negócios com } \\
\text { este banco }\end{array}$ & & \\
\hline & Pensando nos bancos disponíveis, acho que este é o melhor & & \\
\hline & No futuro vou realizar mais negócios com este banco & & \\
\hline
\end{tabular}




\section{Características da Amostra}

Foram obtidas 241 respostas válidas. O perfil dos respondentes se revelou próximo da distribuição demográfica brasileira, especialmente em relação aos aspectos de sexo, idade e estado civil (Instituto Brasileiro de Geografia e Estatística [IBGE], 2015). Para facilitar a compreensão, as características da amostra são ilustradas em gráficos (Figuras 1 e 2):

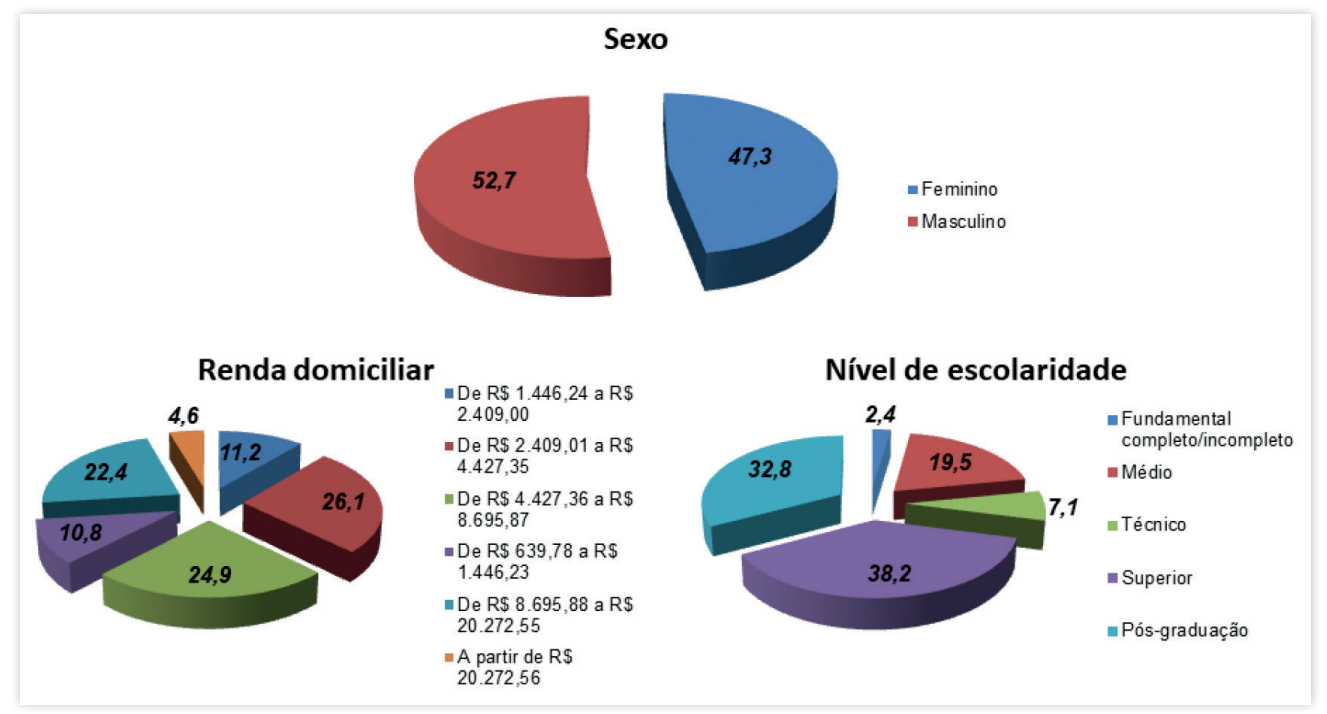

Figura 1. Informações demográficas

Fonte: Dados da pesquisa (2016).

Em relação à amostra coletada nesta pesquisa, os respondentes têm em média 34,9 anos e 47,3\% são do sexo feminino. A renda mensal do domicílio deles tem larga variação, sendo que a maioria recebe de $R \$ 4.427,36$ a $\mathrm{R} \$$ 8.695,87 (24,9\%). Grande parte dos respondentes $(38,2 \%)$ tem ensino superior completo e pós-graduação (32,8\%). Já na Figura 2 podem ser examinadas informações relevantes sobre o contexto bancário em que as falhas/problemas aconteceram.

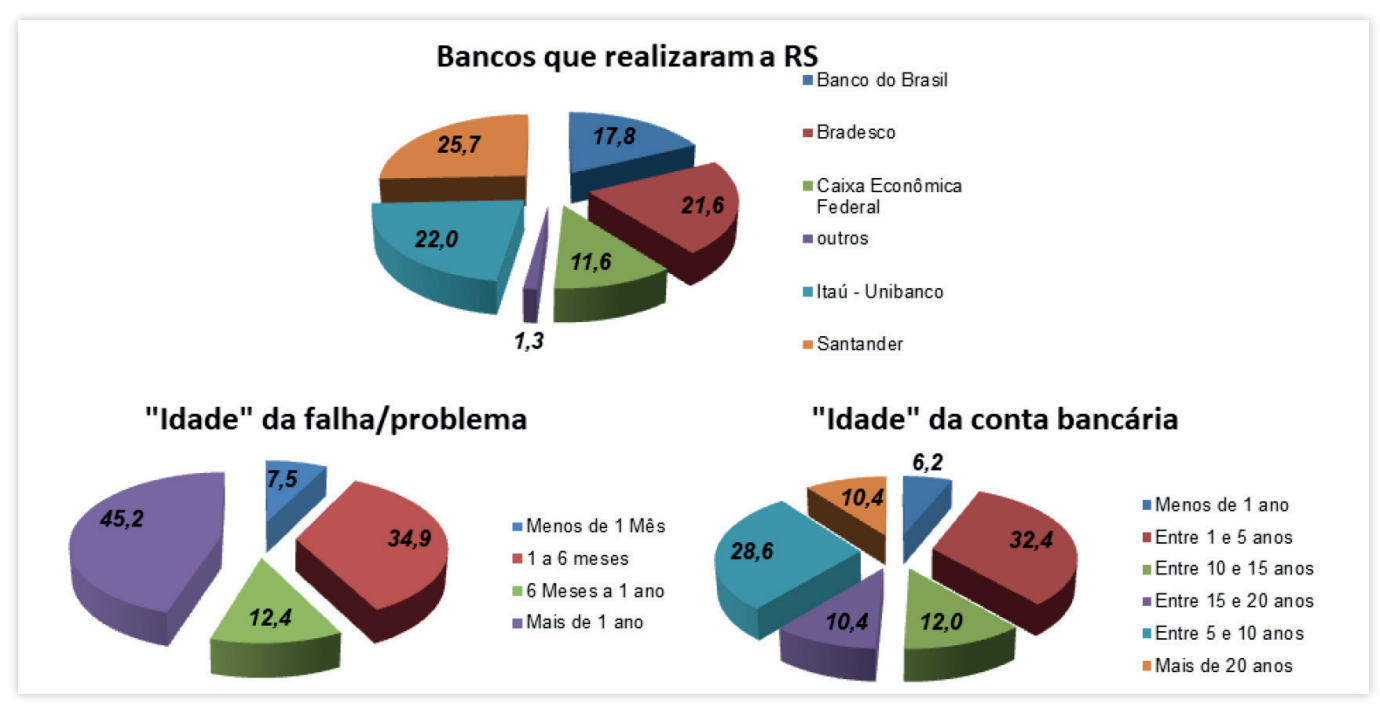

Figura 2. Informações bancárias

Fonte: Dados da pesquisa (2016). 
No que diz respeito aos bancos onde aconteceu o problema e a posterior RS, três deles tiveram médias próximas dos 23\%. Por outro lado, dois outros bancos ficaram abaixo dos $20 \%$. Esses dados merecem atenção por parte dessas instituições, pois o questionário cerceava o respondente em participar apenas com falha/problema que houvesse sido resolvida. Outro dado relevante se refere à idade da falha/problema. De acordo com 34,9\% dos respondentes, no momento de responderem o questionário, seus problemas haviam ocorrido entre 1 e 6 meses bem como 7,5\% há menos de 1 mês. Sendo assim, falhas e problemas em bancos continuam acontecendo em percentual relevante. Em última instância, cabe frisar que os respondentes afirmaram que os problemas ocasionados pelo banco eram muito importantes/graves $(M=6,15)$. Foi utilizada apenas uma variável para mensuração desta questão (ver Tabela 1).

\section{Análise dos dados}

\section{Validação da escala de Equidade}

Para validação dos construtos relacionados à equidade foram realizadas análises fatoriais. A Análise Fatorial Exploratória (AFE) no pré-teste já havia sugerido que as dimensões de equidade se distribuíam em apenas dois fatores. Mesmo após os ajustes na escala, a AFE realizada com as 241 respostas coletadas apontou a existência de duas dimensões. Isto é, as equidades interacional e processual se mesclaram, representando juntas o mesmo fator, ao passo que a equidade distributiva representou o seu próprio fator. Mesmo assim, uma análise fatorial confirmatória, utilizando os cinco construtos propostos no modelo foi realizada.

Com base no tamanho da amostra, a técnica adotada foi a Máxima Verossimilhança (Schermelleh-Engel, Moosbrugger, \& Müller, 2003). O software escolhido foi o Analysis of Moment Structures (AMOS) versão 24. Primeiro realizou-se uma análise do ajuste do modelo. Nessa análise verificouse $u m X^{2}=329,78, g l=195$. Para os índices de ajuste absoluto e incremental, os valores encontrados foram: $G F I=0,89 ; \quad A G F I=0,86$; $R M S E A=0,05$; $\mathrm{NFI}=0,91 ; \mathrm{CFI}=0,96 ; \mathrm{TLI}=0,95$ e $\mathrm{IFI}=0,96$. Esses resultados apontaram que o modelo multidimensional (cinco construtos - considerando três dimensões da equidade) possuía ajuste adequado.

No entanto, a análise da validade convergente e discriminante indicou que não havia validade discriminante entre os construtos de equidade interacional e processual. $\mathrm{Na}$ análise da validade discriminante dessas dimensões foi encontrado o valor de 0,69 para a correlação quadrática entre ambos, sendo que a variância extraída da equidade interacional foi de 0,61 e a processual foi de 0,70. Isto é, ao invés da obtenção de um valor ínfimo que demonstrasse que um construto é distinto do outro, chegou-se à conclusão de que estatisticamente tais construtos estavam, na verdade, sendo semelhantes ou ainda que podem ser representados de maneira conjunta sob a ótica do respondente. Sendo assim, este trabalho retornou à literatura a fim de investigar a possibilidade de interações entre as dimensões de equidade, como aconteceu na validação dos construtos nesta pesquisa. 


\section{Hipóteses sobre possíveis interações entre as dimensões de Equidade}

Sobre o construto de equidade, Tax e Brown (2000) afirmam que são necessárias ações por parte dos funcionários de atendimento, que envolvem resultado/solução (Equidade Distributiva), processo (Equidade Processual) e interação (Equidade Interacional), logo, percebe-se que há certa correlação entre todas as dimensões. Por outro lado, parece que o que as une é a dimensão interacional, afinal é ela quem executa o processo e entrega a solução da RS. De igual modo, recordando o trabalho de Tax et al. (1998), Smith et al. (1999) reconhecem que apesar das dimensões de equidade serem apresentadas como eventos distintos que podem ocorrer em sequência, eles creem que na prática essas situações podem ocorrer de forma combinada ou até mesmo se sobrepondo uma sobre as outras.

Segundo Tax et al. (1998) é possível que haja interação entre as dimensões interacional e processual. Isto é, pode acontecer de uma dimensão ser influenciada pela outra, como um atendimento cortês (interacional) ocorrer também na percepção do cliente como um atendimento flexível (processual). Para Mattila e Patterson (2004), dado que os funcionários são responsáveis pelos processos, as suas qualidades de interação influenciam a equidade processual, tanto de forma positiva como negativa, isto é, "uma boa explicação pode não ser percebida, se o tempo para que a mesma fosse dada foi lento" (Conlon \& Murray,1996, p. 1051).

Andreassen (2000) em seu estudo utiliza apenas uma dimensão, denominada equidade, que capta questões relacionadas à solução e à explicação dada em relação à RS. Já McCllough et al. (2000) e Mattila e Patterson (2004), optam em seus trabalhos pelo uso de duas dimensões (interacional e distributiva). Orsingher, Valentini \& De Angelis (2010) fizeram uma meta-análise, que clarifica bem os diferentes empregos das dimensões de equidade nos artigos sobre RS. Estratégias essas que talvez tenham sido realizadas justamente diante das incongruências apresentadas e reconhecidas pela literatura. Para Santos e Fernandes (2007), essas divergências relacionadas à equidade podem ter relação com a dificuldade do cliente em avaliar os procedimentos da empresa, bem como as diferenças culturais existentes entre nações. Tais diferenças realmente existem e afetam a percepção do cliente no momento de avaliar a equidade da RS (Matos \& Leis, 2013; Patterson, Cowley, \& Prasongsukarn, 2006; Wang \& Mattila, 2011).

Contudo, outra possível motivação para essas interações seria o fato dos clientes terem uma visão em relação ao serviço diferente da empresa e seus gestores. Dado que as empresas de serviços dependem dos funcionários de atendimento para controlar e comunicar a imagem do serviço que é ofertado (Grayson \& Shulman, 2000), a empresa e o funcionário parecem ser um só personagem, sendo difícil separar o que são ações e processos do que são características de uma interação como cortesia, esforço e empatia. Desta forma, parece que a equidade tenta dividir e propor a mensuração de construtos que parecem ser um só. 
No entanto, talvez o mais importante dos motivos para essa divergência entre as equidades seja o fato da maioria dos serviços ser dividida em atividades de back office e front office. Em grande parte deles, o cliente só assiste as atividades de front, isto é, as que exigem interação por parte do funcionário, o que dificulta a percepção das ações processuais ou até mesmo a noção de que elas existem. De modo geral, as atividades de front requerem elementos mais humanos (Grayson \& Shulman, 2000; Lovelock \& Wright, 2002) como educação, esforço e empatia. Já as atividades de back são aquelas que os clientes não podem ver e que, portanto, não podem influenciar a percepção deles, como as ações processuais de controle e flexibilidade. Interessante que talvez seja possível excetuar-se dessa miopia a velocidade do processo, que para o cliente, muitas vezes é percebida como a velocidade do funcionário. Ainda, segundo Lovelock e Wright (2002), as atividades de back office pouco interessam ao cliente, ou seja, são consideradas sem importância, uma vez que ele parece não conseguir opinar ou ainda interpretar como "qualquer coisa". Giovanis et al. (2015), por exemplo, explicam em seu estudo sobre reparos automotivos, que neste tipo de serviço, os clientes não conseguem avaliar facilmente a qualidade porque os serviços de reparo não são visíveis a eles. Assim, eles avaliam apenas o resultado final, ou seja, o carro reparado.

Por fim, cabe relembrar que vários trabalhos anteriores e posteriores ao advento da equidade tratam a RS como um conjunto de ações ou processo que busca resultados, isto é, trabalhos nos quais a RS é tratada como duas unidades (Gohary et al., 2016; Kelley et al., 1993; Johnston \& Michel, 2008; Tax \& Brown, 1998). Nestes, o resultado é uma solução satisfatória entregue ao cliente e o processo, que é permeado por diversas ações, é importante para se chegar até ela, sendo que ambos têm papel central na satisfação do cliente (Zemke \& Bell, 1990). Isso corrobora a percepção de duas dimensões de equidade: uma relacionada à experiência de serviço, que envolve o processo e a interação, e outra ligada ao resultado do serviço ou solução para a RS. Sendo assim, após as análises fatoriais (exploratória e confirmatória) e da própria literatura, este trabalho sugere a junção dos construtos de equidade interacional e processual, propondo ainda o termo equidade da experiência para representá-los. Seguindo a mesma lógica, sugere-se o termo equidade da solução para a equidade distributiva. Desta forma, é necessária a reformulação das hipóteses (Tabela 3):

Tabela 3. Hipóteses reformuladas

H1: 0 empoderamento dos funcionários de atendimento influencia positivamente a lealdade dos clientes após a RS.

H2a: A equidade da experiência influencia positivamente a lealdade do cliente após a RS.

H2b: A equidade da solução influencia positivamente a lealdade do cliente após a RS.

H3a: 0 empoderamento dos funcionários de atendimento influencia positivamente a equidade da experiência.

H3b: 0 empoderamento dos funcionários de atendimento influencia positivamente a equidade da solução. 
Nesta linha o modelo foi alterado analisando-se a equidade como bidimensional e não tridimensional. Em relação ao novo ajuste do modelo, o $\mathrm{X} 2=389,16, \mathrm{gl}=198$, foi novamente significante, ao passo que o $\mathrm{X}^{2 / 9 \mathrm{l}}=1,96$. Os índices de ajuste absoluto e incrementais ficaram com: GFI=0,87; AGFI=0,83; RMSEA=0,06; $N F I=0,89 ; C F I=0,94 ; T L I=0,93$ e IFI=0,94. Após esse ajuste inicial percebeu-se que seria necessária a covariância interna de erro entre algumas variáveis dos construtos examinados. Esses ajustes eram necessários e plausíveis, dado que tais variáveis se assemelhavam em seus significados (ver Tabela 1). Nessa linha, os construtos de empoderamento, equidade da experiência e lealdade receberam esses ajustes (ver Figura 3). Após a união dos construtos de equidade interacional e processual que foram convertidos em um único construto, isto é, na equidade da experiência, foi realizada nova análise em relação às validades convergente e discriminante, além da correlação entre os construtos (Tabela 4):

Tabela 4. Validade convergente, discriminante e correlação entre construtos

\begin{tabular}{lcccc}
\hline \multicolumn{1}{c}{ Construtos } & Empoderamento & Lealdade & Equidade da Experiência & Equidade da solução \\
\hline Empoderamento & $\mathbf{0 , 6 5}$ & & & \\
Lealdade & 0,10 & $\mathbf{0 , 7 0}$ & & \\
Equidade da Experiência & 0,05 & 0,26 & $\mathbf{0 , 5 0}$ & \\
Equidade da Solução & 0,03 & 0,21 & 0,34 & $\mathbf{0 , 7 4}$ \\
\hline
\end{tabular}

Fonte: Dados da pesquisa (2016).

Além disso, buscando descobrir possível variância comum de métodos, foi examinado um modelo unidimensional, no qual todas as variáveis eram reflexo de um único fator versus o modelo teórico efetivamente testado. O modelo unidimensional teve $X^{2}=1.747,07, g l=224$ e $X^{2 / 9 l}=7,79$. Os índices de ajuste absoluto e incremental tiveram os seguintes resultados: $\mathrm{GFI}=0,56$; AGFI=0,50; RMSEA=0,16; $N F I=0,54 ; \quad C F I=0,57 ; \quad T L I=0,56$ e $I F I=0,57$. Esses resultados mostram o ajuste ruim do modelo unifatorial, sugerindo a inexistência de variância comum de método.

\section{Resultados}

Diante das mudanças anteriormente propostas e realizadas, o modelo a ser avaliado por equações estruturais é evidenciado na Figura 3. Para esse modelo foi examinado novamente se o ajuste era adequado: $X^{2}=440,94$, $g l=198$, igualmente significante, ao passo que o $X^{2 / g l}=2,23$. Na sequência, os índices de ajuste absoluto e incremental alcançaram os valores: $\mathrm{GFI}=0,86$; AGFI=0,82; RMSEA=0,07; NFI=0,88; CFI=0,93; TLI=0,92 e IFI=0,93. 


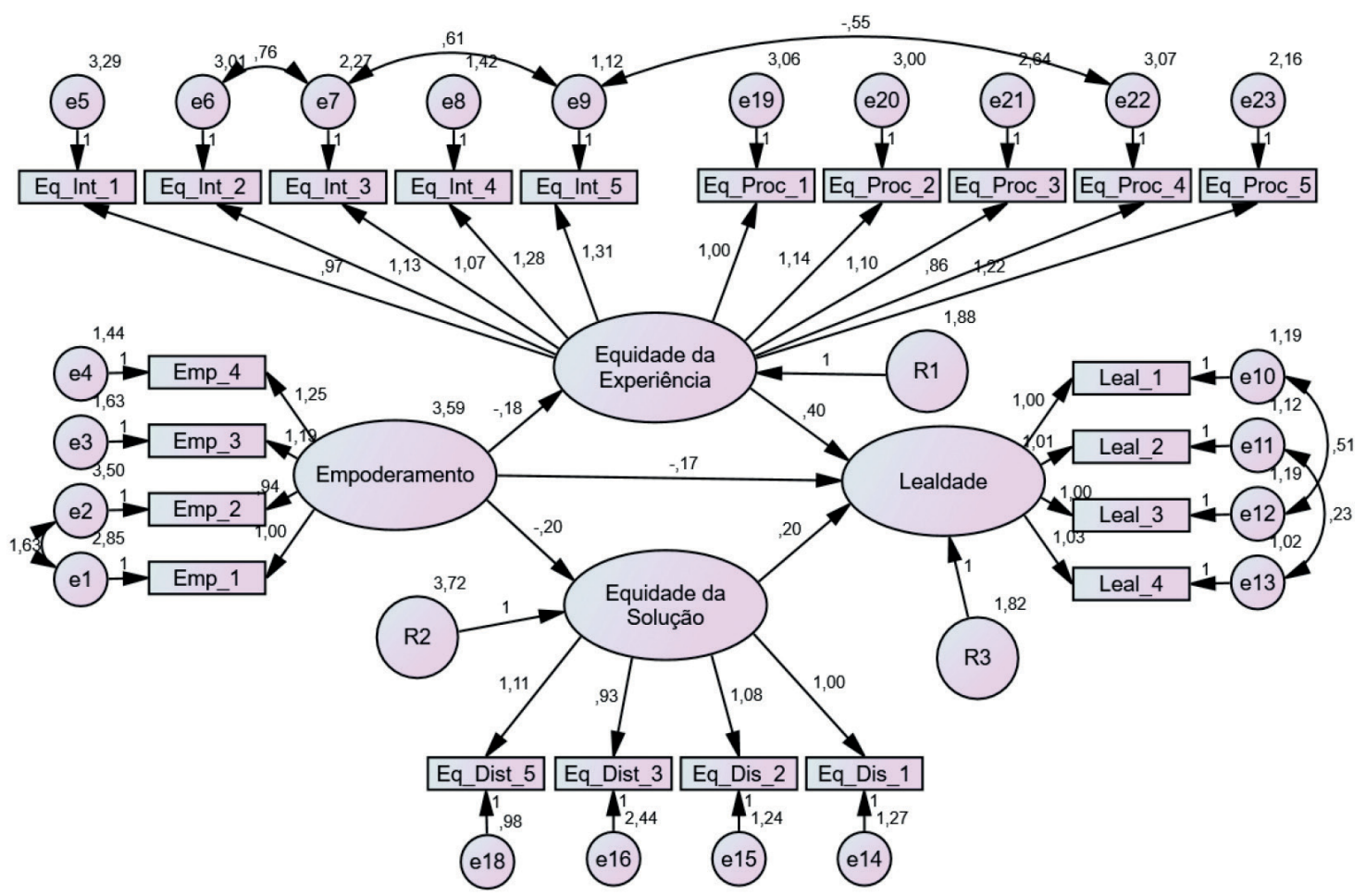

Figura 3. Modelo avaliado por equações estruturais

Fonte: Output AMOS 24.

Uma vez validado o modelo de mensuração, utilizou-se a modelagem por equações estruturais para testar as hipóteses. Esta técnica permite examinar diversas relações entre variáveis latentes e observadas, dependentes e/ou independentes (Cooper \& Schindler, 2011). Além disso, ela permite que se trabalhe com um modelo que pode ser a representação de uma teoria ou o conjunto de relações que nela podem existir para se explicar um fenômeno (Hair, Black, Babin, Anderson, \& Tatham, 2009), como proposto neste estudo (Ver Figura 3). De acordo com a Tabela 2, a modelagem testou todas as hipóteses sugeridas neste trabalho. A associação direta do empoderamento dos funcionários de atendimento em relação à lealdade do cliente para com a empresa de serviços depois da RS foi significante $(\beta=2,96 ; p=0,003)$. Além disso, o empoderamento também afetou a equidade da experiência de RS $(\beta=3,25 ; p=0,001)$. Essa influência positiva do empoderamento também se repetiu em relação à equidade da solução fornecida pela $R S(\beta=2,73$; $\mathrm{p}=0,006)$.

Por fim, os resultados tanto da equidade da experiência de $R S$ ( $\beta=4,74$; $p=0,001)$ como da equidade da solução da $R S(\beta=3,77 ; p=0,001)$ levam à lealdade do cliente com a empresa de serviços. Esses resultados merecem atenção, pois demonstram que as dimensões de equidade exercem relevante impacto mediador entre o empoderamento dos funcionários e a lealdade dos clientes após o processo de RS. Comparando-se as dimensões de equidade, a da experiência $(\beta=4,74)$, revelou ser a que mais media esta relação. Portanto, de modo geral, todas as hipóteses deste estudo foram confirmadas (ver Tabela 5). 
Tabela 5. Teste de hipóteses

\begin{tabular}{|c|c|c|c|c|c|c|c|c|}
\hline \multicolumn{3}{|c|}{ Análise de caminhos } & \multirow{2}{*}{$\frac{\text { Estimativa }}{0,17}$} & \multirow{2}{*}{$\frac{\text { E. P. }}{0,06}$} & \multirow{2}{*}{$\frac{\beta}{2,96}$} & \multirow{2}{*}{$\frac{p \text { valor }}{0,003}$} & \multirow{2}{*}{$\frac{\text { Hipóteses }}{\text { H1 }}$} & \multirow{2}{*}{$\begin{array}{c}\text { Teste de } \\
\text { Hipóteses } \\
\text { Confirmada }\end{array}$} \\
\hline Empoderamento & $\rightarrow$ & Lealdade & & & & & & \\
\hline $\begin{array}{l}\text { Equidade da } \\
\text { Experiência }\end{array}$ & $\rightarrow$ & Lealdade & 0,40 & 0,08 & 4,74 & 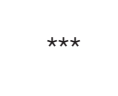 & $\mathrm{H} 2 \mathrm{a}$ & Confirmada \\
\hline Equidade da Solução & $\rightarrow$ & Lealdade & 0,20 & 0,05 & 3,77 & 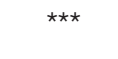 & $\mathrm{H} 2 \mathrm{~b}$ & Confirmada \\
\hline Empoderamento & $\rightarrow$ & $\begin{array}{l}\text { Equidade da } \\
\text { Experiência }\end{array}$ & 0,18 & 0,06 & 3,25 & 0,001 & H3a & Confirmada \\
\hline Empoderamento & $\rightarrow$ & $\begin{array}{l}\text { Equidade da } \\
\text { Solução }\end{array}$ & 0,20 & 0,07 & 2,73 & 0,006 & $\mathrm{H} 3 \mathrm{~b}$ & Confirmada \\
\hline
\end{tabular}

Fonte: Dados da pesquisa (2016).

\section{Discussão, conclusão e contribuições}

O presente trabalho se propôs a examinar o relacionamento e seus efeitos entre os construtos de empoderamento, equidade e lealdade na RS. Esse exame foi realizado através de um survey com clientes de bancos, que passaram por falhas/problemas e posterior RS $(n=241)$. Para a análise dos dados utilizou-se o software Analysis of Moment Structures (AMOS) versão 24. As técnicas estatísticas empregadas foram: a Análise Fatorial Exploratória (AFE), Análise Fatorial Confirmatória (AFC) e a Modelagem por Equações Estruturais (MEE).

Primeiramente, a relação entre empoderamento e lealdade se mostrou positiva e significante $(\mathrm{H} 1)$. Observando-se as variáveis dos construtos empoderamento e lealdade desta pesquisa (Ver Tabela 1), os resultados mostram que, em situações problemáticas, o atendimento com poder de decisão e objetivo, que não fica passando de um funcionário para o outro e finalmente é resolvido, cria por parte do cliente a lealdade com a empresa de serviços que realizou a RS. Desta forma, este cliente passa a falar coisas boas sobre a empresa, incentiva pessoas a usarem seus serviços, entende que esta é a melhor empresa disponível e, sempre que possível, busca tal empresa para novas experiências ou negócios. Esses achados validam afirmações teóricas da literatura que sugeriam esta relação, isto é, que situações problemáticas em que há um atendimento com poder de decisão poderia gerar como contrapartida do cliente a sua lealdade com a empresa que recuperou o serviço (Bowen \& Lawler, 1992; Eccles \& Durand, 1998). Por outro lado, confirma os outros trabalhos empíricos voltados à perspectiva de operações, que já previam em parte esta relação (Craighead et al., 2004; Miller et al., 2000).

De igual modo, os resultados encontrados levaram à confirmação da segunda hipótese $(\mathrm{H} 2 \mathrm{a} / \mathrm{H} 2 \mathrm{~b})$, demonstrando que a equidade, tanto na experiência como na solução entregue ao cliente, gera a lealdade do mesmo em relação à empresa que recuperou o serviço. Ou seja, diante de problemas em serviços, quando a empresa e seus funcionários demonstram equilíbrio, igualdade e de certa forma justiça no atendimento desses problemas, 
tanto na experiência (interação e processo) quanto na solução, os clientes percebem essas características e se propõem a serem leais com a empresa. Esses resultados confirmam outros estudos empíricos (Giovanis et al., 2015; Kau \& Loh, 2006; Mattila, 2001; Santos \& Fernandes, 2007; Silva \& Lopes, 2014; Smith et al., 1999).

Esse achado reforça a necessidade de se descobrir novas ações e processos de tratamento para falhas e problemas em serviços que aumentem a equidade, os quais também podem aumentar a satisfação e a lealdade dos clientes (Conlon \& Murray, 1996). Isso confirma também os resultados de alguns estudos, que propõem que a RS não tem buscado apenas a satisfação de seus clientes, mas também a sua lealdade (Chou, 2015; Kim, Kim, \& Kim, 2009; Miller et al., 2000; Smith et al.,1999).

Neste trabalho, por exemplo, foi sugerido que o empoderamento poderia ser uma dessas ações. Essa sugestão, analisada empiricamente, confirmou as hipóteses $(\mathrm{H} 3 \mathrm{a} / \mathrm{H} 3 \mathrm{~b})$ levantadas no decorrer da revisão teórica. Isto é, o empoderamento realmente influencia a equidade da experiência. Isso confirma os pressupostos encontrados na literatura científica, como: a obtenção de respostas mais rápidas (Bowen \& Lawler, 1992, 1995; Smith \& Karwan, 2010); melhor qualidade na interação cliente e funcionário de atendimento (Daily \& Huang, 2001; Lashley, 1998; Li \& Fang, 2016); e flexibilidade no processo de RS (Boshoff \& Allen, 2000; Chebat \& Kollias, 2000; Hill, 2000; Sok \& O'Cass, 2015). Ou seja, as características que compõem a equidade da experiência têm seus níveis de desempenho ampliadas, dada a influência do empoderamento.

Da mesma forma isso ocorre com a equidade da solução da RS $(\mathrm{H} 3 \mathrm{~b})$. Os resultados mostraram que o empoderamento pode impactar características que compõem a equidade da solução, como: soluções do ponto de vista do cliente (Brown et al., 1996); atendimento proporcional à circunstância e necessidades dos clientes (Sasser \& Fulmer, 1990; Tax \& Brown, 1998), acarretando, assim, em soluções mais assertivas (Grönroos, 2009; Schlesinger \& Heskett, 1991). Essas características atendem aos princípios de necessidade, igualdade e proporção que clientes com problemas esperam em termos de solução (Tax et al.,1998). Assim, o empoderamento dos funcionários leva a uma melhor percepção de equidade da solução. Esses achados corroboram os estudos recentes, que argumentam que o empoderamento implica em atitudes positivas do pessoal de atendimento, principalmente em situações problemáticas (Zhang et al., 2015), gerando retornos positivos para as empresas de serviços (Chase \& Haynes, 2000; Leão et al., 2017; Sok \& O'Cass, 2015; Van Looy et al., 2003).

Combinados, esses achados apontam que a equidade medeia a relação entre empoderamento e lealdade $(\mathrm{H} 2 \mathrm{a} / \mathrm{H} 2 \mathrm{~b})$. Esse achado permite entender o motivo pelo qual o empoderamento gera lealdade - isto é, o empoderamento confere uma maior percepção de equidade ao processo de RS. Assim, ao empoderar seus funcionários, é necessário que as empresas os orientem a agir de forma que o processo de recuperação pareça mais equilibrado/justo. Dessa forma, tal ação pode potencializar a recuperação e a manutenção da lealdade dos clientes. Contudo, apesar da equidade mediar a relação entre empoderamento e lealdade, há ainda outras variáveis não 
capturadas por esse modelo que também podem mediar essa relação. De qualquer forma, a descoberta do papel mediador da equidade é importante, pois ela demonstra criar mais força entre empoderamento e lealdade, isto é, as equidades da experiência (> impacto) e da solução (< impacto) revelaram-se mediadoras entre esses construtos:

$$
\text { Empoderamento } \rightarrow \frac{\text { Equidade da Experiência }}{\text { Equidade da Solução }} \rightarrow \text { Lealdade }
$$

Seguindo as sugestões de Miller et al. (2000) e Tax e Brown (1998), além dos trabalhos de Boshoff (2005), Boshoff e Leong (1998) e Boshoff e Allen (2000), uma das contribuições teóricas deste trabalho é a incorporação do empoderamento dos funcionários de atendimento no processo de RS. Este acréscimo é realizado de maneira focada, de forma a mostrar sua influência positiva nas dimensões de equidade, ainda que duas delas tenham sido examinadas como uma só (equidade da experiência), o que deixa mais evidente ainda que o cliente percebe melhores ações de atendimento. Uma segunda contribuição diz respeito ao fato da equidade poder ser um caminho a ser percorrido (mediação) para que o empoderamento proporcione a lealdade dos clientes depois de eventos de RS (relacionamento este que a literatura em RS ainda não havia discutido). Essa análise é importante dado que as dimensões de equidade são responsáveis por relacionar cliente e empresa de serviço (Ozuem et al., 2017). Desta forma, este trabalho sugere que novos estudos sejam replicados, examinando o impacto do empoderamento de funcionários de atendimento junto aos clientes com problemas em serviços.

O empoderamento, por ser um fator antecedente em diversos outputs da RS, é uma estratégia operacional que necessita ser planejada com cautela e tempo. Além disso, cada vez mais a literatura reconhece que a RS precisa ser concebida como um sistema (Smith, Nagy, Karwan, \& Ramirez, 2012; Zhang et al., 2015). Por isso, mais recentemente, a literatura de RS tem reconhecido a necessidade de receber e promover insights para as áreas de Marketing, Operações e RH (Michel et al., 2009). Apesar das dificuldades em aplicar um modelo mais robusto que influencie essa tríade presente na RS, a maioria dos trabalhos em RS contribui para uma ou duas dessas áreas (Leão, 2016). Portanto, a integração de diferentes conceitos dessas áreas é a terceira contribuição teórica deste trabalho. Seguindo as recomendações de Goldstein et al. (2002) e Leão (2016), buscou-se preencher em parte esta lacuna ao trazer um modelo que integrasse essas vertentes através da conjugação de construtos que fazem parte de cada campo específico, como o empoderamento (Operações), que precisa da seleção e treinamento adequado das pessoas que vão recebê-lo $(R H)$ e que traz benefícios para a equidade e a lealdade em serviços (Marketing).

Nesta linha, aprender com falhas e problemas pode ser mais importante do que simplesmente recuperar clientes individualmente. Logo, a Gestão de Operações contribui significativamente na RS (Zhang et al., 2015), dado que a mesma tem foco em decisões e melhorias operacionais, tanto de gestão como de projeto (Hayes, Pisano, \& Upton, 1996). Por outro lado, 
quando precisa-se analisar o fator cliente além do processo ou operação, a gestão deve ter em mente conceitos do Marketing (Leão et al., 2017), como as dimensões de equidade (Smith et al., 2012). Afinal, a equidade trata de processos psicológicos abstratos, que envolvem ações bidirecionais e se desenvolvem quando duas ou mais partes se relacionam (Ozuem et al., 2017). Finalmente, como os esforços ou estratégias de RS dependem em grande parte dos funcionários de atendimento, é necessário que os mesmos sejam bem selecionados e estejam preparados $(R H)$ para exercerem a RS (Boshoff, 1997, 1999; Boshoff \& Allen, 2000).

Sob o prisma prático, sugere-se que as empresas de serviços que pretendem obter melhor desempenho, seja em gestão de reclamações, satisfação/lealdade dos clientes, eficiência e melhoria em operações de atendimento, podem implementar ações para promover o empoderamento de seus funcionários, pois isso pode trazer maiores níveis de equidade e satisfação na resolução de problemas (Pranic \& Rhoel, 2012; Tax \& Brown, 2000) bem como a lealdade dos clientes (Gremler \& Brown, 1996; Ogbeide et al., 2017). Variável essa que, em último grau, contribui para a lucratividade das empresas (De Ruyter \& Wetzels, 2000; Hart et al., 1990; Johnston \& Michel, 2008; Ogbeide et al., 2017). Além disso, melhorar processos como os da RS inclui uma melhor alocação dos recursos humanos. Para isso, treinamento e novas oportunidades são fundamentais para que os funcionários aumentem seus conhecimentos e contribuam com o melhor de suas habilidades (Deming, 1990). Sugere-se também a realização de treinamentos específicos em RS para os funcionários de atendimento, para que estes saibam atuar em situações de maior empoderamento. Em síntese, treinamentos em RS e o empoderamento de funcionários de atendimento ao longo do tempo podem se tornar competências únicas na prestação de serviços, que não são fáceis de duplicar e que geram valor ao cliente (Bowen \& Lawler, 1995). Interessante que mesmo com esse tipo de informação à disposição, muitos executivos não implementam melhorias na experiência de serviço, pois acham que elas não geram resultados atraentes para seus negócios (Michelli, 2013). Portanto, empresas e gestores precisam realizar avaliações minuciosas quanto ao retorno do investimento realizado em gestão, como treinamento e empoderamento dos funcionários versus resultados esperados, como: lealdade, percentual de problemas resolvidos satisfatoriamente e/ou maior receita de vendas (Bowen, Schneider, \& Kim, 2000; Van Looy et al., 2003). Desse modo será possível verificar o percentual de retorno/utilidade ou não da estratégia operacional a ser implantada.

\section{- Limitações e recomendações para futuras pesquisas}

Neste momento, este trabalho apresenta suas limitações, como o fato da amostra abordada ser focada em falhas e problemas de serviços bancários. Serviços estes que, ao mesmo tempo, possuem características como alta intensidade de mão de obra no processo de serviço (repetição) e alta aplicação de conhecimento analítico quando algo dá errado e precisa ser resolvido. Tais características nem sempre estão presentes em outros serviços. 
Uma segunda limitação foi a impossibilidade de se examinar a equidade como tridimensional. Todavia, essa limitação merece novos estudos que aprofundem a questão sobre como o cliente enxerga o processo de serviço e a sua recuperação, dado que questões culturais parecem interferir neste sentido (Matos \& Leis, 2013; Patterson et al., 2006; Wang \& Mattila, 2011). A terceira e última limitação está relacionada à forma como foi mensurado o construto empoderamento. No caso do presente estudo, o mesmo foi avaliado do ponto de vista dos clientes e não do funcionário de atendimento, o que de certa forma seria mais concreto. Novos estudos podem realizar este feito, baseando-se no trabalho de Boshoff e Allen (2000) que avaliaram o empoderamento (cinco variáveis) do ponto de vista do funcionário de atendimento.

Como sugestões para futuras pesquisas, esse trabalho propõe novos estudos que avaliem o construto de empoderamento como fator antecedente para outros construtos, sejam eles mediadores ou não, como: falhas pouco ou muito graves, lucratividade, diminuição de falhas/problemas, melhorias nas operações de atendimento, qualidade em serviços, satisfação e recomendações boca a boca. Sugere-se também que o empoderamento pode ser analisado juntamente com a cocriação do cliente no processo de RS (Dong et al., 2008; Guo et al., 2016), examinando-se como se comportam esses construtos, de forma a buscar satisfação ou lealdade do cliente reclamante. Outra possibilidade seria verificar como o cliente reclamante interfere em situações de "improvisação" na RS (Cunha, Rego, \& Kamoche, 2009). Por fim, dado que a maioria dos trabalhos sobre equidade remontam à década de 1990, que foi encerrada há quase 20 anos, novos trabalhos qualitativos poderiam reavaliar as características que compõem cada uma das dimensões de equidade em diferentes contextos nacionais, avaliando-se como hábitos e culturas podem vir a modificar suas dimensões.

\section{Agradecimentos}

Agradecemos aos editores e revisores da Revista Eletrônica de Ciência Administrativa RECADM pelos comentários e sugestões em versões anteriores deste manuscrito.

\section{Referências}

Andreassen, T. W. (2000). Antecedents to satisfaction with service recovery. European Journal of Marketing, 34(1/2), 156-175.

Ashill, N. J., Rod, M., \& Carruthers, J. (2008). The effect of management commitment to service quality on frontline employees' job attitudes, turnover intentions and service recovery performance in a new public management context. Journal of Strategic Marketing, 16(5), 437-462.

Bambauer-Sachse, S., \& Rabeson, L. E. (2015). Service recovery for moderate and high involvement services. Journal of Services Marketing, 29(5), 331-343. 
Bateson, J. G., \& Hoffman, E. K. D. (2001). Marketing de Serviços. 4 ed. Porto Alegre: Bookman.

Bell, C. R., \& Zemke, R. E. (1987). Service breakdown: the road to recovery. Management review, 76(10), p. 32.

Berry, L. L. (1996). Serviços de satisfação máxima: guia prático de ação. Rio de Janeiro: Campus.

Bitner, M. J., Booms, B. H., \& Tetreault, M. S. (1990). The service encounter: diagnosing favorable and unfavorable incidents. The Journal of Marketing,54(1) p. 71-84.

Blodgett, J. G., Hill, D. J., \& Tax, S. S. (1997). The effects of distributive, procedural, and interactional justice on postcomplaint behavior. Journal of retailing, 73(2), 185-210.

Boshoff, C. (1997). An experimental study of service recovery options. International Journal of service industry management, 8(2), 110-130.

Boshoff, C. (2005). A re-assessment and refinement of RECOVSAT: An instrument to measure satisfaction with transaction-specific service recovery. Managing. Service Quality: An International Journal, 15(5), 410-425.

Boshoff, C., \& Allen, J. (2000). The influence of selected antecedents on frontline staff's perceptions of service recovery performance. International Journal of Service Industry Management, 11(1), 63-90.

Boshoff, C., \& Leong, J. (1998). Empowerment, attribution and apologising as dimensions of service recovery: An experimental study. International Journal of Service Industry Management, 9(1), 24-47.

Bowen, D. E., \& Johnston, R. (1999). Internal service recovery: developing a new construct. International Journal of Service Industry Management, 10(2), 118-131.

Bowen, D. E., \& Lawler, E. E. (1992). The empowerment of service workers: what, why, how, and when. Sloan Management Review, 33(3), 31-40.

Bowen, D. E., \& Lawler, E. E. (1995). Empowering service employees. Sloan management review, 36(4), 73.

Bowen, D. E., Schneider, B., \& Kim, S. S. (2000). Shaping service cultures through strategic human resource management. In: Swartz, T., \& lacobucci, D. Handbook of services marketing and management. Sage, 439-454.

Brown, S. W. (2000). Practicing best-in-class service recovery. Marketing Management, 9(2), 8-9.

Brown, S. W., Cowles, D. L., \& Tuten, T. L. (1996). Service recovery: its value and limitations as a retail strategy. International Journal of Service Industry Management, 7(5), 32-46.

Chase, R. B., \& Haynes, R. M. (2000). Service operations management: A field guide. In: . Handbook of services marketing and management. Sage, 455-471.

Chebat, J. C., \& Kollias, P. (2000). The impact of empowerment on customer contact employees' roles in service organizations. Journal of Service research, 3(1), 66-81.

Choi, B., \& Choi, B. J. (2014). The effects of perceived service recovery justice on customer affection, loyalty, and word-of-mouth. European Journal of Marketing, 48(1/2), 108-131. 
Choi, C. H., Kim, T. T., Lee, G., \& Lee, S. K. (2014). Testing the stressor-strainoutcome model of customer-related social stressors in predicting emotional exhaustion, customer orientation and service recovery performance. International Journal of Hospitality Management, 36 (1), 272-285.

Chou, P. F. (2015). An analysis of the relationship between service failure, service recovery and loyalty for Low Cost Carrier travelers. Journal of Air Transport Management, 47 (1), 119-125.

Colgate, M., \& Norris, M. (2001). Developing a comprehensive picture of service failure. International Journal of Service Industry Management, 12(3), 215-233.

Conlon, D. E., \& Murray, N. M. (1996). Customer perceptions of corporate responses to product complaints: The role of explanations. Academy of Management Journal, 39(4), 1040-1056.

Cooper, D. R., \& Schindler, S.P. Métodos de Pesquisa em Administração. 10 ed. Porto Alegre: Bookman, 2011.

Craighead, C. W., Karwan, K. R., \& Miller, J. L. (2004). The effects of severity of failure and customer loyalty on service recovery strategies. Production and Operations Management, 13(4), 307-321.

Crisafulli, B., \& Singh, J. (2016). Service guarantee as a recovery strategy: The impact of guarantee terms on perceived justice and firm motives. Journal of Service Management, 27(2), 117-143.

Cunha, M. P., Rego, A., \& Kamoche, K. (2009). Improvisation in service recovery. Managing Service Quality: An International Journal, 19(6), 657-669.

Daily, B. F., \& Huang, S. C. (2001). Achieving sustainability through attention to human resource factors in environmental management. International Journal of Operations \& Production Management, 21(12), 1539-1552.

De Ruyter, K., \& Wetzels, M. (2000). Customer equity considerations in service recovery: a cross-industry perspective. International Journal of Service Industry Management, 11(1), 91-108.

Deming, W. E. (1990). Qualidade: A revolução da administração. Rio de Janeiro: Marques Saraiva.

DeWitt, T., \& Brady, M. K. (2003). Rethinking service recovery strategies the effect of rapport on consumer responses to service failure. Journal of Service Research, 6(2), 193-207.

Dong, B., Evans, K. R., \& Zou, S. (2008). The effects of customer participation in cocreated service recovery. Journal of the academy of marketing science, 36(1), 123-137.

Duffy, J. A. M., Miller, J. M., \& Bexley, J. B. (2006). Banking customers' varied reactions to service recovery strategies. International Journal of Bank Marketing, 24(2), 112-132.

Eccles, G., \& Durand, P. (1998). Complaining customers, service recovery and continuous improvement. Managing Service Quality: An International Journal, 8(1), 68-71.

Edvardsson, B. (1992). Service breakdowns: A study of critical incidents in an airline. International Journal of Service Industry Management, 3(4), 17-29.

Edvardsson, B., \& Roos, I. (2001). Critical incident techniques: Towards a framework for analysing the criticality of critical incidents. International Journal of Service Industry Management, 12(3), 251-268. 
Edvardsson, B., Tronvoll, B., \& Höykinpuro, R. (2011). Complex service recovery processes: how to avoid triple deviation. Managing Service Quality: An International Journal, 21(4), 331-349.

Giovanis, A., Athanasopoulou, P., \& Tsoukatos, E. (2015). The role of service fairness in the service quality-relationship quality-customer loyalty chain: An empirical study. Journal of Service Theory and Practice, 25(6), 744-776.

Gohary, A., Hamzelu, B., \& Pourazizi, L. (2016). A little bit more value creation and a lot of less value destruction! Exploring service recovery paradox in value context: A study in travel industry. Journal of Hospitality and Tourism Management, 29 (1), 189-203.

Goldstein, S. M., Johnston, R., Duffy, J., \& Rao, J. (2002). The service concept: the missing link in service design research?. Journal of Operations management, 20(2), 121-134.

Grayson, K., \& Shulman, D. (2000). Impression management in services marketing In:___. Handbook of services marketing and management. Sage, 51-67.

Gremler, D. D., \& Brown, S. W. (1996). Service loyalty: its nature, importance, and implications. Advancing service quality: A global perspective, p. 171-180.

Grönroos, C. (1988). Service quality: the six criteria of good perceived service. Review of business, 9(3), p. 10.

Grönroos, C. (2009). Marketing: gerenciamento e serviços. Rio de Janeiro: Elsevier.

Guo, L., Lotz, S. L., Tang, C., \& Gruen, T. W. (2016). The role of perceived control in customer value cocreation and service recovery evaluation. Journal of Service Research, 19(1), 39-56.

Hair, J. F., Black, W. C., Babin, B. J., Anderson, R. E., \& Tatham, R. L. (2009). Análise multivariada de dados. Porto Alegre: Bookman.

Hart, C. W., Heskett, J. L., \& Sasser, W. E. (1990). The profitable art of service recovery. Harvard business review, 68(4), 148-156.

Hayes, R. H., Pisano, G. P., \& Upton, D. M. (1996). Strategic Operations. New York: Harvard Business School.

Hess, R. L., Ganesan, S., \& Klein, N. M. (2003). Service failure and recovery: The impact of relationship factors on customer satisfaction. Journal of the Academy of Marketing Science, 31(2), p.127.

Hill, T. (2000). Operations Management: Strategic Context and Management Analysis. Londres: MacMillan Business.

Hocutt, M. A., Bowers, M. R., \& Donavan, D. T. (2006). The art of service recovery: fact or fiction?. Journal of Services Marketing, 20(3), 199-207.

Hoffman, K. D., Kelley, S. W., \& Rotalsky, H. M. (1995). Tracking service failures and employee recovery efforts. Journal of Services Marketing, 9(2), 49-61.

Ibge. (2015). Síntese de indicadores sociais. Uma análise das condições de vida da população brasileira. Rio de Janeiro: IBGE.

Johnston, R. (1995). Service failure and recovery: impact, attributes and process. In: Swartz, T; Bowen, D. E., \& Brown, S.W. Advances in Services Marketing and Management: Research and Practice, 4(1), 211-228. 
Johnston, R., \& Fern, A. (1999). Service recovery strategies for single and double deviation scenarios. Service Industries Journal, 19(2), 69-82.

Johnston, R., \& Michel, S. (2008). Three outcomes of service recovery: customer recovery, process recovery and employee recovery. International Journal of Operations \& Production Management, 28(1), 79-99.

Johnston, R., Clark, G., \& Shulver, M. (2012). Service operations management. Harlow, FT/Pearson Education.

Johnston, R.; Mehra, S. (2002). Best-practice complaint management. The Academy of Management Executive, 16(4), 145-154.

Jones, H., \& Farquhar, J. D. (2007). Putting it right: service failure and customer loyalty in UK banks. International Journal of Bank Marketing, 25(3), 161-172.

Kau, A-K., \& Loh, E. W-Y. (2006). The effects of service recovery on consumer satisfaction: a comparison between complainants and non-complainants. Journal of Services Marketing, 20(2), 101-111.

Kelley, S. W., Hoffman, K. D., \& Davis, M. A. (1993). A typology of retail failures and recoveries. Journal of retailing, 69(4), 429-452.

Kim, T. T., Kim, W. G., \& Kim, H. B. (2009). The effects of perceived justice on recovery satisfaction, trust, word-of-mouth, and revisit intention in upscale hotels. Tourism management, 30(1), 51-62.

Lashley, C. (1998). Matching the management of human resources to service operations. International Journal of Contemporary Hospitality Management, 10(1), 24-33.

Leão, W. (2016). Empoderamento e Satisfação na Recuperação do Serviço: Os Efeitos da Compensação e do Lócus de Controle do Cliente. Dissertação de mestrado, Fundação Educacional Inaciana Padra Sabóia de Medeiros (FEl), São Paulo, SP, Brasil.

Leão, W., Santos, J.B., Hernandez, J. M. C. (2017). Employee empowerment as a strategy to increase satisfaction with service recovery and the moderating role of service external locus of control. Anais do XLI EnAnpad - Encontro Nacional de Pós- Graduação em Administração, São Paulo, SP, Brasil.

Lewis, B. R., \& Clacher, E. (2001). Service failure and recovery in UK theme parks: The employees' perspective. International Journal of Contemporary Hospitality Management, 13(4), 166-175.

Li, C. Y., \& Fang, Y. H. (2016). How online service recovery approaches bolster recovery performance? A multi-level perspective. Service Business, 10(1), 179-200.

Lorenzoni, N., \& Lewis, B. R. (2004). Service recovery in the airline industry: a cross-cultural comparison of the attitudes and behaviours of British and Italian front-line personnel. Managing Service Quality: An International Journal, 14(1), 11-25.

Lovelock, C., \& Wright, L. (2002). Serviços: Marketing e Gestão. São Paulo: Saraiva.

Matos, C. A., \& Leis, R. P. (2013). The antecedents of complaint behaviour for Brazilian and French consumers of services. International Journal of Consumer Studies, 37(3), 327-336.

Matos, C. A., Henrique, J., \& Rossi, A. (2007). Service recovery paradox: a meta-analysis. Journal of service research, 10(1), 60-77. 
Mattila, A. S. (2001). The effectiveness of service recovery in a multi-industry setting. Journal of Services Marketing, 15(7), 583-596.

Mattila, A. S., \& Patterson, P. G. (2004). Service recovery and fairness perceptions in collectivist and individualist contexts. Journal of Service Research, 6(4), 336-346.

McColl-Kennedy, J. R., \& Sparks, B. A. (2003). Application of fairness theory to service failures and service recovery. Journal of Service Research, 5(3), 251-266.

McCollough, M. A., \& Gremler, D. D. (2004). A conceptual model and empirical examination of the effect of service guarantees on post-purchase consumption evaluations. Managing Service Quality: An International Journal, 14(1), 58-74.

McCollough, M. A., Berry, L. L., \& Yadav, M. S. (2000). An empirical investigation of customer satisfaction after service failure and recovery. Journal of Service Research, 3(2), 121-137.

Michel, S. (2004). Consequences of perceived acceptability of a bank's service failures. Journal of Financial Services Marketing, 8(4), 367-377.

Michel, S., Bowen, D., \& Johnston, R. (2009). Why service recovery fails: Tensions among customer, employee, and process perspectives. Journal of Service Management, 20(3), 253-273.

Michelli, J. (2013). Receita para a excelência: os princípios que fizeram da UCLA um dos maiores sistemas de saúde dos Estados Unidos (e as lições que você pode tirar para o seu negócio). Porto Alegre: Bookman.

Migacz, S. J., Zou, S., \& Petrick, J. F. (2018). The "Terminal" Effects of Service Failure on Airlines: Examining Service Recovery with Justice Theory. Journal of Travel Research, 57(1), 83-98.

Miller, J. L., Craighead, C. W., \& Karwan, K. R. (2000). Service recovery: a framework and empirical investigation. Journal of operations Management, 18(4), 387-400.

Moliner-Velázquez, B., Ruiz-Molina, M. E., \& Fayos-Gardó, T. (2015). Satisfaction with service recovery: moderating effect of age in word-of-mouth. Journal of Consumer Marketing, 32(6), 470-484.

Ogbeide, G. C. A., Böser, S., Harrinton, R. J., \& Ottenbacher, M. C. (2017). Complaint management in hospitality organizations: The role of empowerment and other service recovery attributes impacting loyalty and satisfaction. Tourism and Hospitality Research, 17(2), 204-216.

Orsingher, C., Valentini, S., \& de Angelis, M. (2010). A meta-analysis of satisfaction with complaint handling in services. Journal of the Academy of Marketing Science, 38(2), 169-186.

Ozuem, W., Patel, A., Howell, K. E., \& Lancaster, G. (2017). An exploration of consumers' response to online service recovery initiatives. International Journal of Market Research, 59(1), 97-115.

Park, J., \& Ha, S. (2016). Co-creation of service recovery: Utilitarian and hedonic value and post-recovery responses. Journal of Retailing and Consumer Services, 28(1), 310-316.

Patterson, P. G., Cowley, E., \& Prasongsukarn, K. (2006). Service failure recovery: The moderating impact of individual-level cultural value orientation on perceptions of justice. International Journal of Research in Marketing, 23(3), 263-277. 
Pranic, L., \& Roehl, W. S. (2012). Rethinking servicerecovery: Acustomerempowerment (CE) perspective. Journal of Business Economics and Management, 13(2), 242-260.

Ramachandran, A., \& Chidambaram, V. (2012). A review of customer satisfaction towards service quality of banking sector. Periodica Polytechnica Social and Management Sciences, 20(2), 71-79.

Río-Lanza, A. B., Vázquez-Casielles, R., \& Díaz-Martín, A. M. (2009). Satisfaction with service recovery: Perceived justice and emotional responses. Journal of Business Research, 62(8), 775-781.

Robinson, L., Neeley, S. E., \& Williamson, K. (2011). Implementing service recovery through customer relationship management: identifying the antecedents. Journal of Services Marketing, 25(2), 90-100.

Santos, C. P. D., \& Fernandes, D. V. D. H. (2007). A recuperação de serviços como ferramenta de relacionamento e seu impacto na confiança e lealdade dos clientes. Revista de Administração de Empresas, 48(1), 10-24.

Sasser, W. E., \& Fulmer, W. E. (1990). Creating personalized service delivery systems. In: Bowen, D. E., Chase, R. B., \& Cummings, T. G. Service Management Effectiveness: Balancing Strategy, Organization and Human Resources, Operations and Marketing, p. 213-233. San Francisco, Jossey-Bass.

Schermelleh-Engel, K., Moosbrugger, H., \& Müller, H. (2003). Evaluating the fit of structural equation models: Tests of significance and descriptive goodness-of-fit measures. Methods of psychological research online, 8(2), 23-74.

Schlesinger, L., \& Heskett, J. (1991). Breaking the cycle of failures in services. Sloan Management Review, 32(3), 17-28.

Schneider, B. (1990). Alternative strategies for creating service-oriented organizations. In:__. Service Management Effectiveness: Balancing Strategy, Organization and Human Resources, Operations and Marketing, p. 126-151. San Francisco, Jossey-Bass.

Schneider, B., \& Bowen, D. E. (1995). Winning the service game. Boston: Harvard Business School Press.

Seiders, K., \& Berry, L. L. (1998). Service fairness: What it is and why it matters. The Academy of Management Executive, 12(2), 8-20.

Silva, M. A., \& Lopes, E. L. (2014). A Influência da Justiça nos Processos de Recuperação de Falhas no Varejo. Revista de Administração Contemporânea, 18(1), p. 37.

Slack, N., Brandon-Jones, A., \& Johnston, R. (2018). Administração da produção. 8 ed. São Paulo: Atlas.

Smith, A. K., Bolton, R. N., \& Wagner, J. (1999). A model of customer satisfaction with service encounters involving failure and recovery. Journal of Marketing Research, 36(3)p. 356-372.

Smith, J. S., \& Karwan, K. R. (2010). Empirical profiles of service recovery systems: the maturity perspective. Journal of Service Research, 13(1), 111-125.

Smith, J. S., Karwan, K. R., \& Markland, R. E. (2012). An empirical investigation of the effectiveness of an integrated service recovery system. Operations Management Research, 5(1-2), 25-36. 
Smith, J. S., Nagy, P. F., Karwan, K. R., \& Ramirez, E. (2012). The contingent nature of service recovery system structures. International Journal of Operations \& Production Management, 32(7), 877-903.

Sok, P., \& O'Cass, A. (2015). Achieving service quality through service innovation exploration-exploitation: the critical role of employee empowerment and slack resources. Journal of Services Marketing, 29(2), 137-149.

Stauss, B., \& Weinlich, B. (1997). Process-oriented measurement of service quality: Applying the sequential incident technique. European Journal of Marketing, 31(1), 33-55.

Swanson, S. R., \& Kelley, S. W. (2001). Service recovery attributions and word-of-mouth intentions. European Journal of Marketing, 35(1/2), 194-211.

Tax, S. S., \& Brown, S. W. (1998). Recovering and learning from service failure. Sloan Management Review, 4O(1), p.75.

Tax, S. S., \& Brown, S. W. (2000). Service recovery: research insights and practices. In:__. Handbook of services marketing and management. California, Sage, p. 271-285.

Tax, S. S., \& Brown, S. W.; Chandrashekaran, M. (1998). Customer evaluations of service complaint experiences: implications for relationship marketing. The Journal of Marketing, 62(2)p. 60-76.

Van Looy, B., Krols, K., Buyens, D., \& Vandenbossche, T. (2003). The role of empowerment in service organizations. In: Van Looy, B., Gemmel, P., \& Van Dierdonck, R. Services Management: An Integrated Approach. England: Pearson, 229-242.

Van Looy, B.; Desmet, S.; Krols, K., \& Van Dierdonck, R. (1998) Psychological empowerment in a service environment: Some empirical findings. In: Swartz, T. A., Bowen, D.E., \& Brown, S. W. Advances in Services Marketing and Management, 7, 293-311.

Wang, C. Y., \& Mattila, A. S. (2011). A cross-cultural comparison of perceived informational fairness with service failure explanations. Journal of Services Marketing, 25(6), 429-439.

Wang, K. Y., Hsu, L. C., \& Chih, W. H. (2014). Retaining customers after service failure recoveries: a contingency model. Managing Service Quality, 24(4), 318-338.

Wirtz, J., \& Mattila, A. S. (2004). Consumer responses to compensation, speed of recovery and apology after a service failure. International Journal of service industry management, 15(2), 150-166.

Xu, Y., Marshall, R., Edvardsson, B., \& Tronvoll, B. (2014). Show you care: initiating co-creation in service recovery. Journal of Service Management, 25(3), 369-387.

Zeithaml, V. A., Parasuraman, A., \& Berry, L. L. (2014). A excelência em serviços. São Paulo: Saraiva.

Zemke, R., \& Bell, C. (1990). Service recovery: Doing it right the second time. Training, 27(6), 42-48.

Zhang, M., Dai, X., \& He, Z. (2015). An empirical investigation of service recovery in e-retailing: An operations management perspective. Journal of Service Theory and Practice, 25(3), 348-367. 